IJHER International Journal of Humanities and Educational Research ISSN: 2757-5403

Volume 4, Issue 1, February 2022

Received: 01/12/2021

Accepted: 08/01/2022

Published: 01/02/2022

\title{
THE IMPACT OF DISTANCE EDUCATION ON THE COGNITIVE VALUES OF ALGERIAN STUDENTS SURVEY FROM THE PERSPECTIVE OF THE THEORY OF VALUE INEVITABILITY
}

\section{Yacine SADOUKI 1}

Researcher, Djilali Bounaama University, Algeria

\begin{abstract}
This research paper works in the light of relying on the theory of value determinism in the media by professor Dr. Izzy Abdel Rahman, to research, excavate and explore the impact of the distance learning process through the digital space on the cognitive values of Algerian students, and by applying the survey method and relying on the questionnaire tool as a main tool and the observation tool as a secondary tool, We chose the cluster sample; whose vocabulary comes to more than one stage, so we chose the study sample in several stages, and the final number of the study sample was estimated at 483 items, distributed as follows: 152 items were chosen from Djiliali Bounaama University, Khemis Miliana, 136 items were selected from Ibrahim Sultan CHibout University Algeria3, 96 subjects were selected from Ali lounici University Blida2, 100 subjects were selected from Hassiba Ben Bouali University Of Chlef, and all this released By distributing An electronic questionnaire form through a Google form to the study sample students.
\end{abstract}

Key words: Value Determinism Theory İn The Media, Cognitive Values, Distance Education, Algerian University Students.

http://dx.doi.org/10.47832/2757-5403.12.9 


\title{
أثر التعليم عن بعد على القيم المعرفية لاى الطلبة الجزائريين دراسة مسحية من منظور نظرية الحتمية المعية القيمية الطية
}

\author{
ياسبن صدوقي \\ الباحث، جامعة الجيلالي بونعامة خميس مليانة، الجز ائر
}

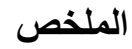

هذه الورقة البحثة تعمل في ضوء الاعتماد على نظرية الحتمية القيمية في الاعلام للأستاذ الدكتور عزي عبد الرحمن،

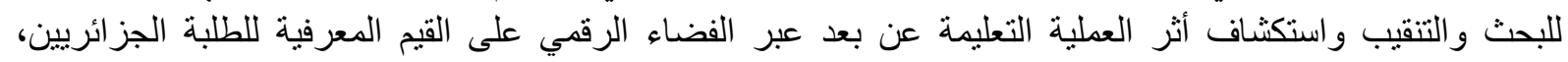

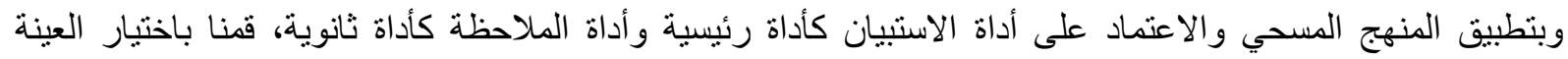



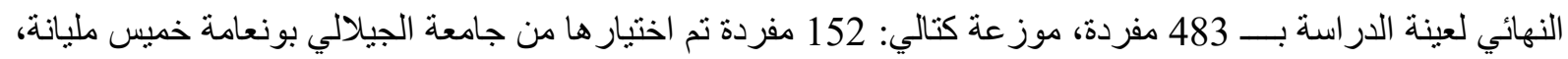

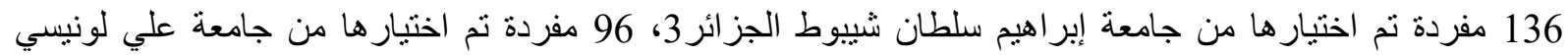

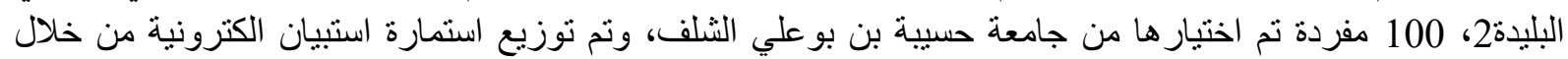
نموذج Google على الطلبة عينة الدراسة. الكلمات المفتاحية: نظرية الحتمية القيمية في الاعلام، القيم المعرفية، التعليم عن بعد، الطلبة الجامعيين الجز ائريين.

مقدمة

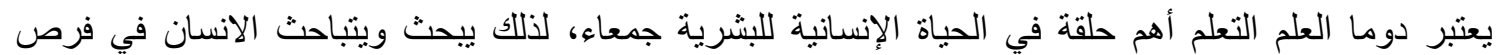

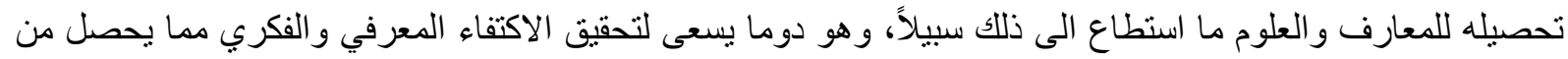

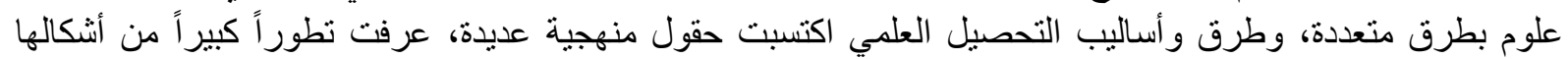

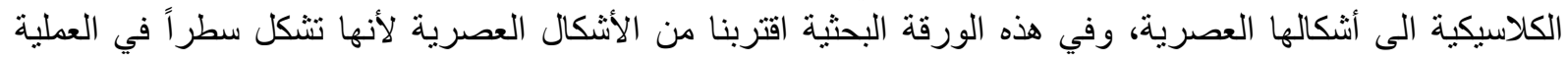

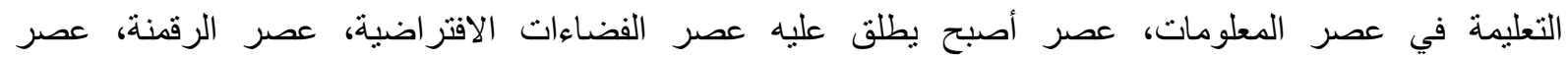



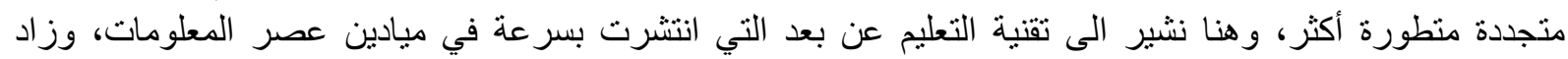

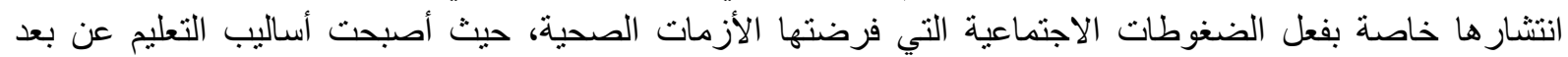

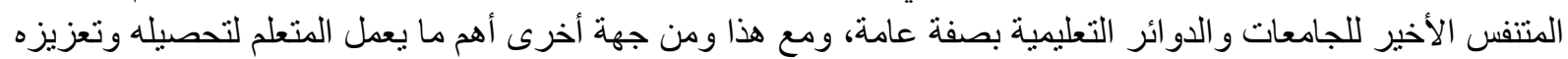

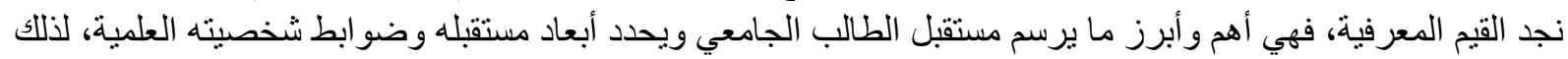

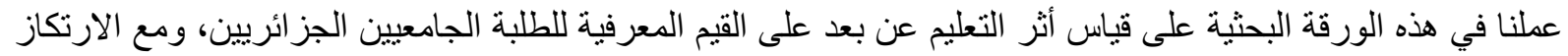

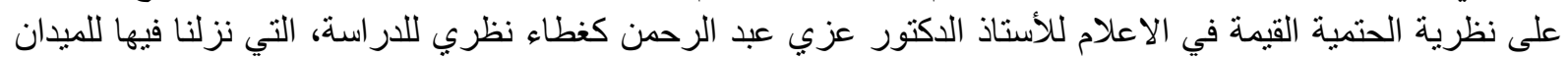

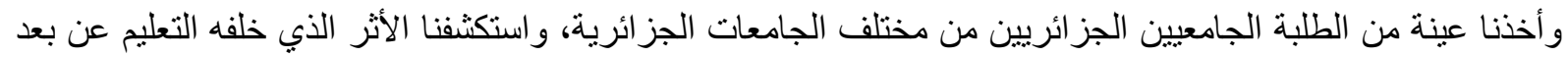
على القيم المعرفية لدى الطلبة الجز ائريين.

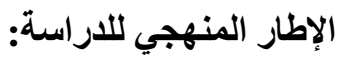 إشكالية الاراسة:}

منذ سنوات عديدة عرفت البشرية وسائل الاعلام التقليدية التي كانت بالنسبة إليهم أهم و عاء فكري بتلقون فيه

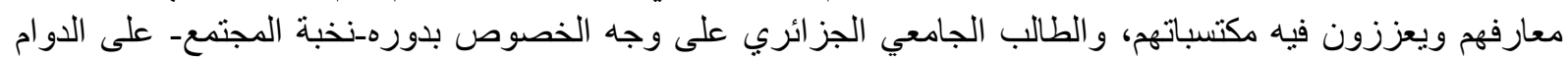

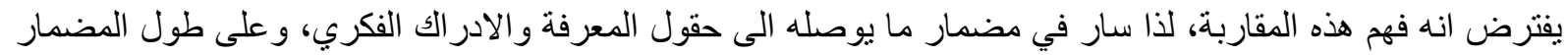

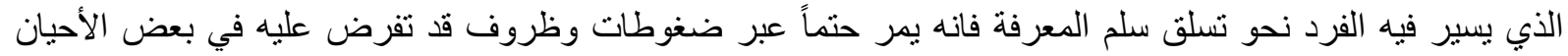

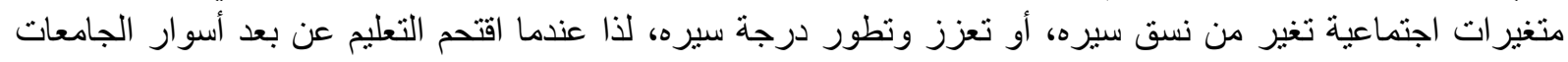

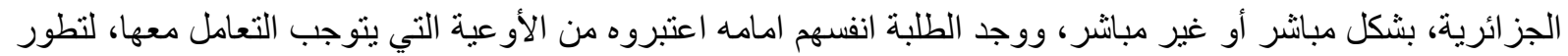

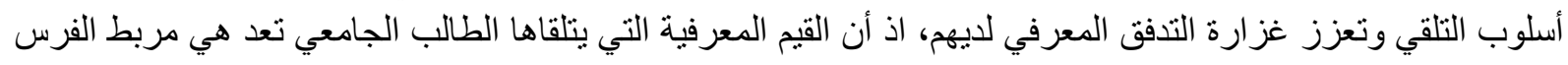

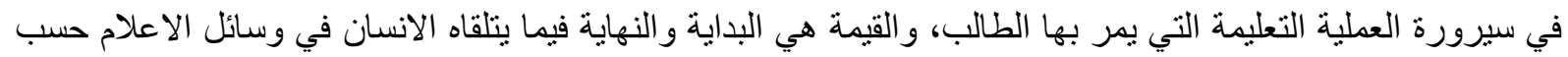


الأستاذ الدكتور عزي عبد الرحمن (عزي، 2013)، وهنا نشير الى وسائل الاعلام سواء كانت تقليدية أو حديثة في صورة

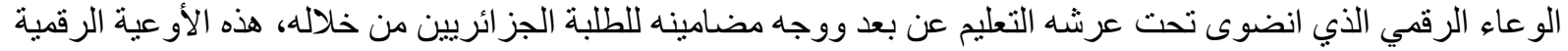

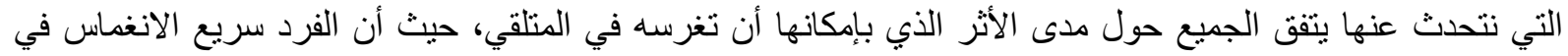

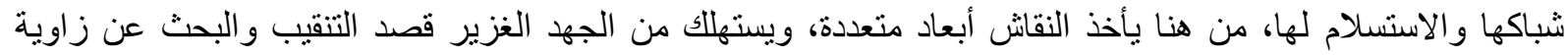



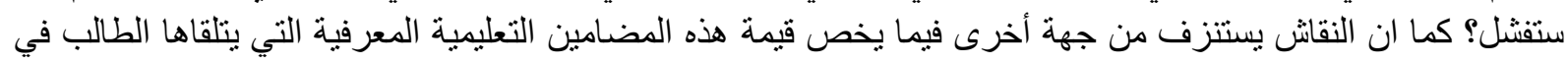

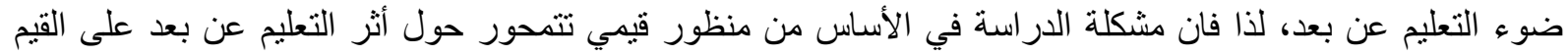

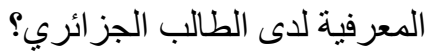

تساؤلات الاراسة:

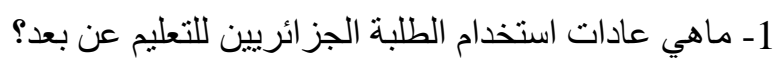

2- ما حجم تعرض الطلبة الجز ائريين للتعليم عن بعد؟

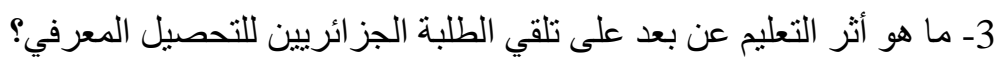

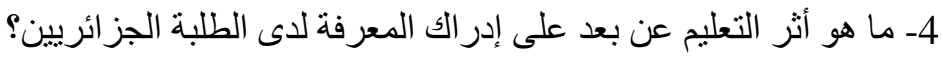

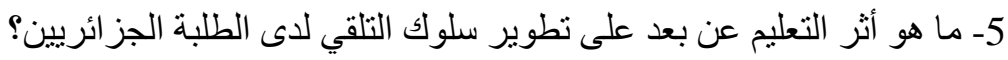

أهمية الار اسة:

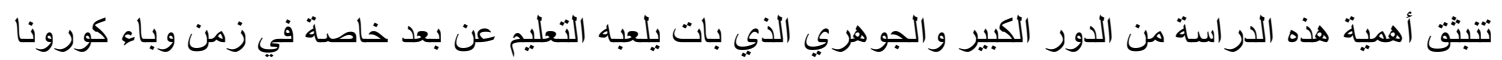
الذي بعثر أور اق العالم، ولا يمكننا ان ننكر أن الفضاء الرقمي قد أنقذ الدول من الاصطدام بشعوبها وطلبتها لإنها بعد الغلق الكلي

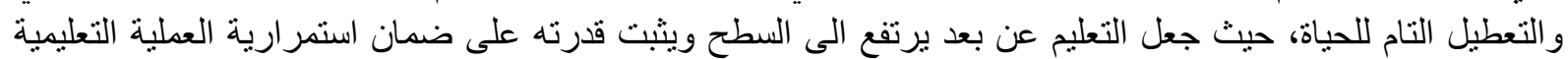

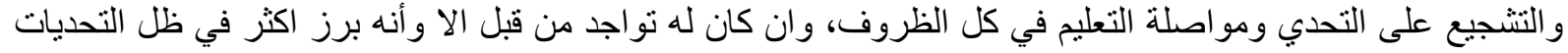

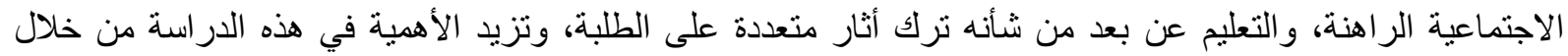

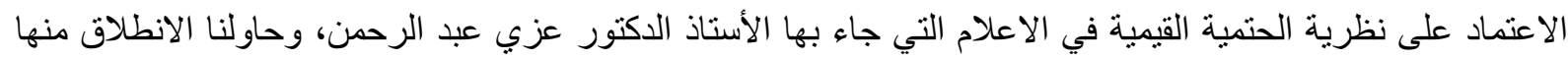

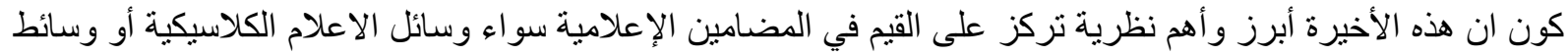

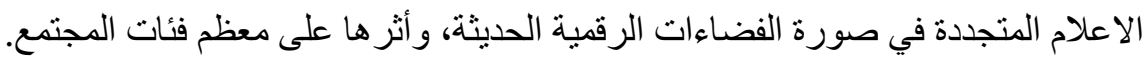

$$
\text { أهداف الدراسة: }
$$

1- فتح الججال أمام الباحثين مستقبلاً من أجل نطبيق نظرية الحتمية القيمية في الاعلام بالدراسات التي تعني بالتعليم و الوسائط الجديدة.

2- الر غبة في اقتر اح وفتح المجال قصد نوظيف نظرية الحنمية القيمية لقياس كل الأثار التي تنعكس على الطلبة الجزائرية في العملية التعليمية.

3ـ التنقيب حول القيم المعرفية التي استخلصها الطالب الجزائري من خلال الولوج لعالم التعليم من البو ابة الرقمية. 4ـ معرفة مدى نجاعة التعليم عن بعد في تعزيز واكساب الطالب الجزائري قيماً نطور تحصيله المعرفي وتعزز مكانته الفكرية. 5ـ محاولة اقتر اح جملة من الأليات والتوصيات لكيفية التعامل مع الوعاء الرقمي في سبيل تلقي قيماً معرفية وفق أصول ومبادئ مجتمعنا الإسلامي. 
تعتمد كل در اسة على السير وفق خطوات فكرية منظمة وعقلانية هادفة لبلوغ نتيجة ما، وما ذلك الا باتباع منهج

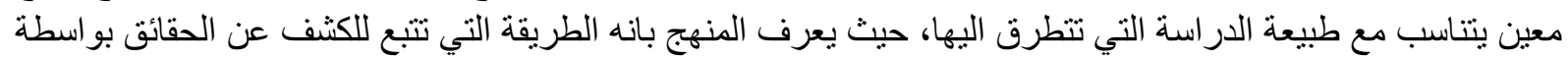

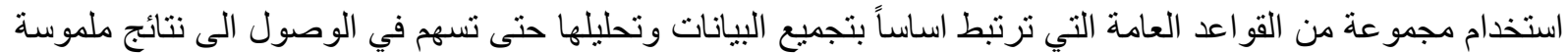

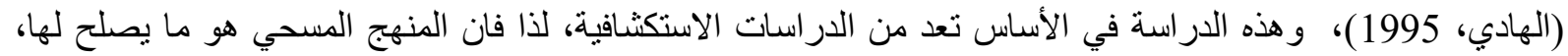

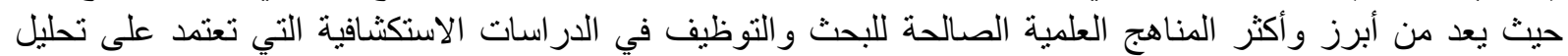

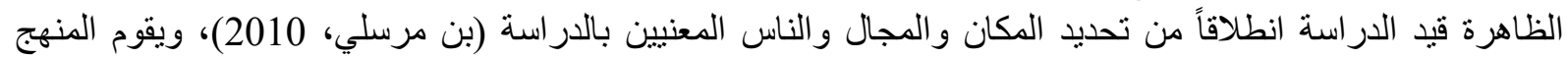

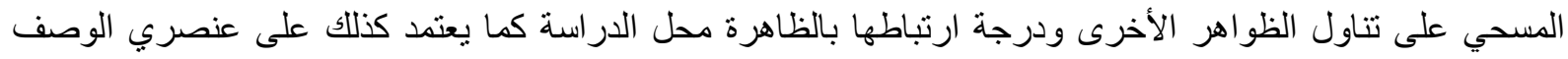

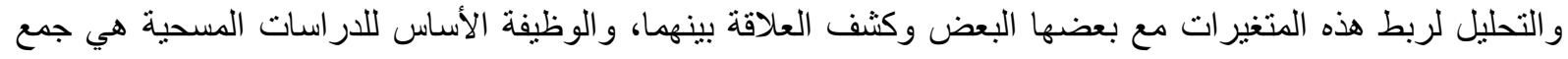

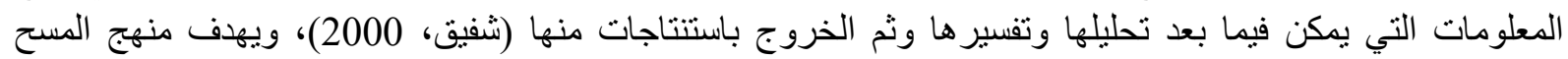

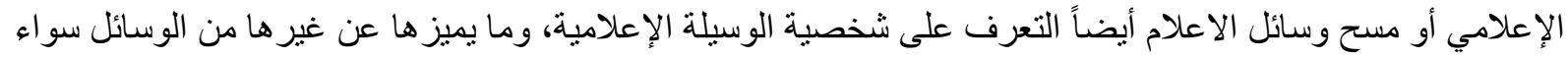

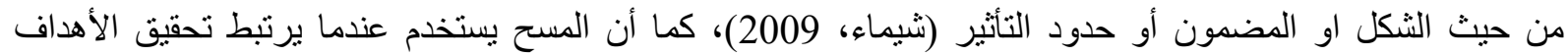

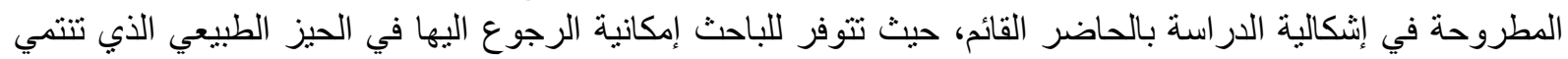

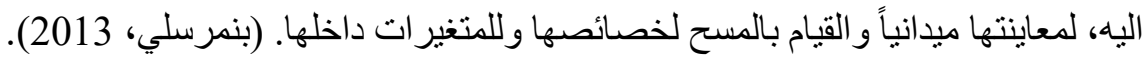

مجتمع الاراسة:

هناك من بطلق عليه مجتمع الدراسة الأصلي ويقصد به كامل أفراد موضوع البحث، ويعرف على ألى أنه مجموعة

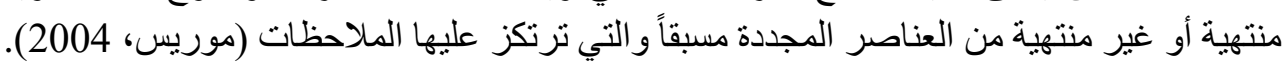

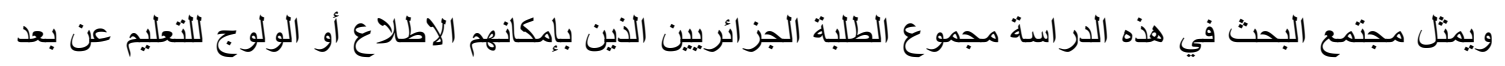



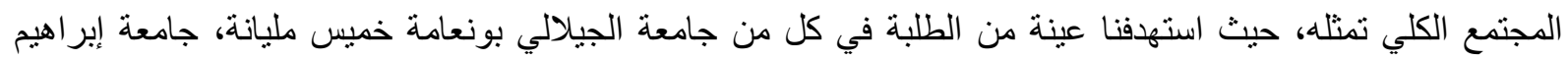

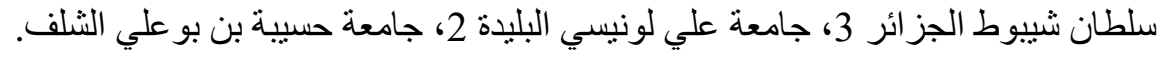

عينة الاراسة:

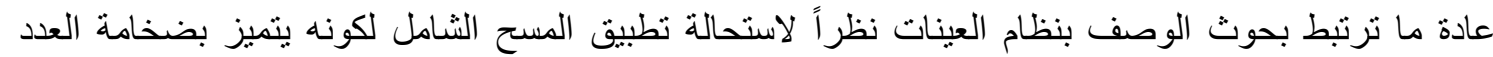

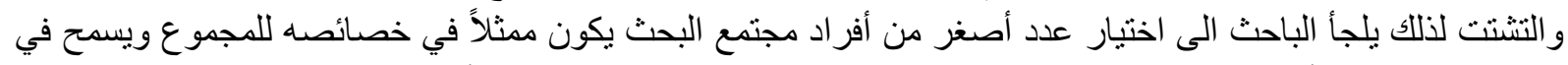

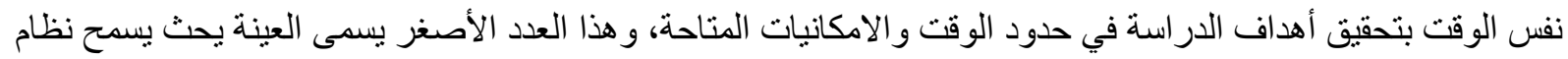

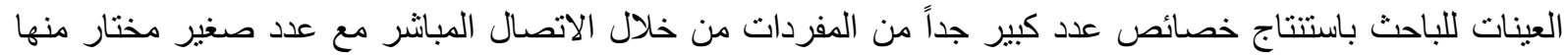

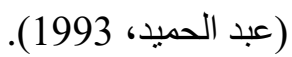

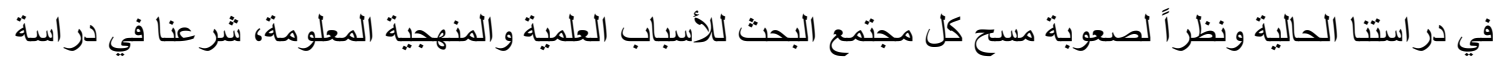

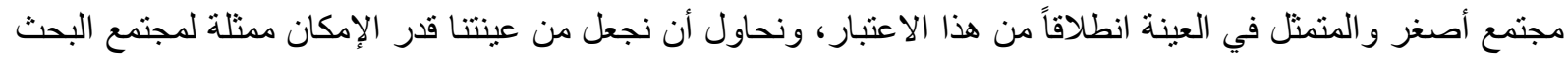

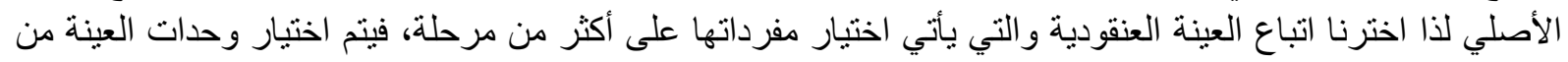

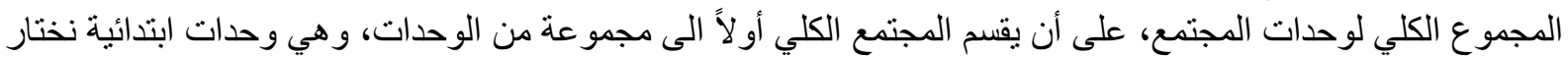

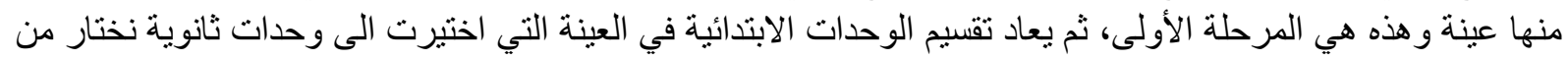
بينها عينة جديدة، وهذه هي المرحلة الثانية و هكذا...

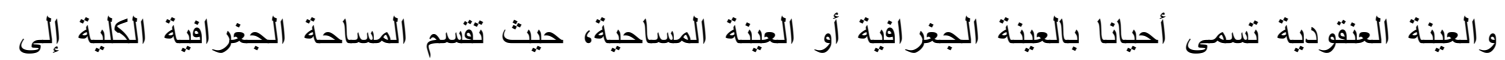

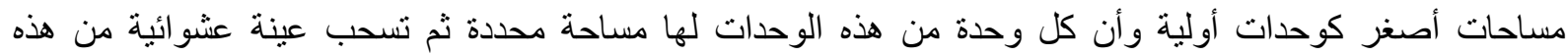

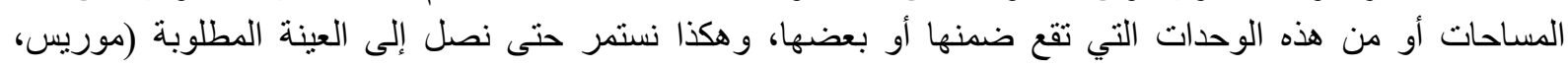

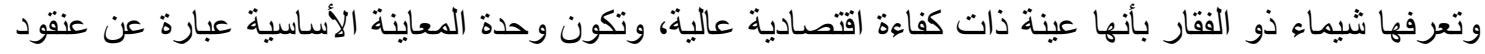

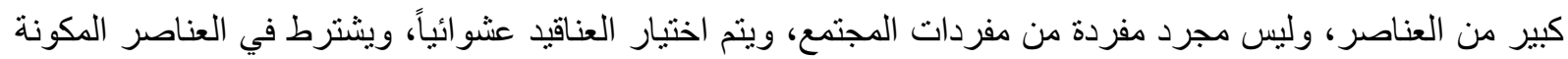


لكل عنقود وجود تقارب_غالباً ما يكون تقارباً كمياً- بينها، وتعد عينة المناطق هي الأكثر استخداماً بين أنواع العينات العنقودية.(شيماء، 2009).

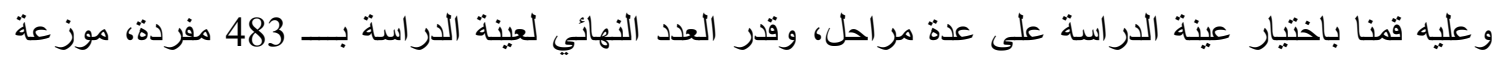

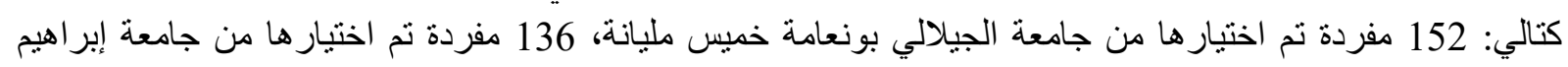

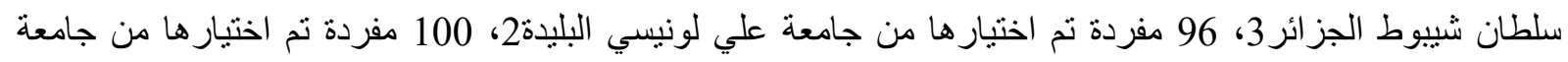

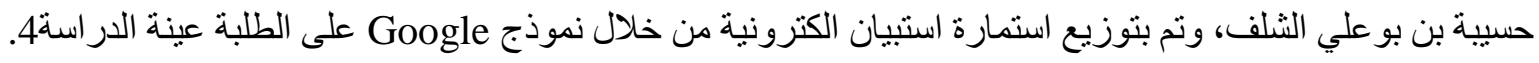

أدوات الاراسة:

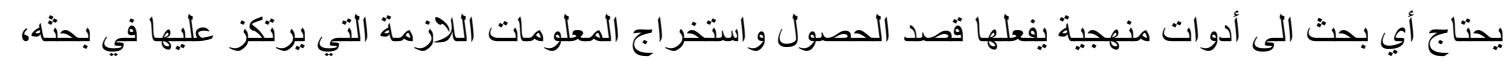

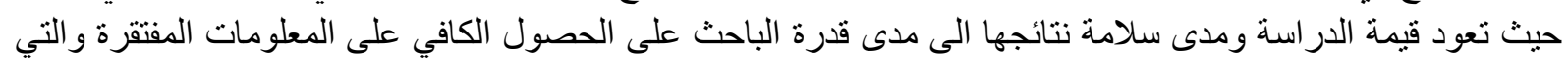

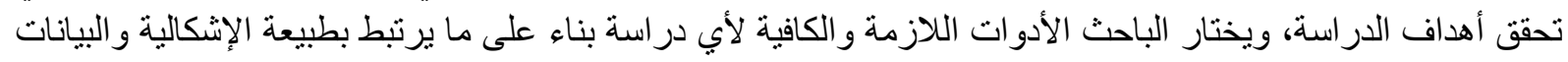

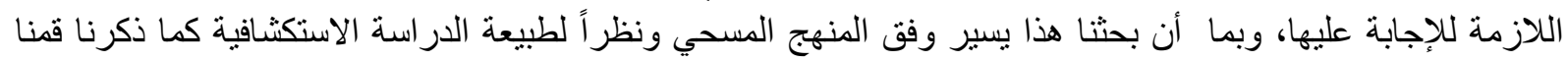

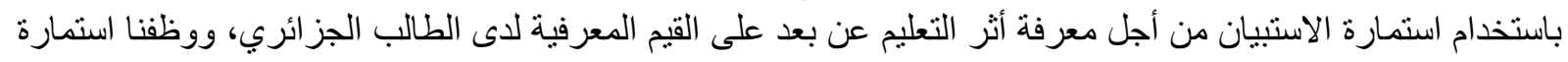

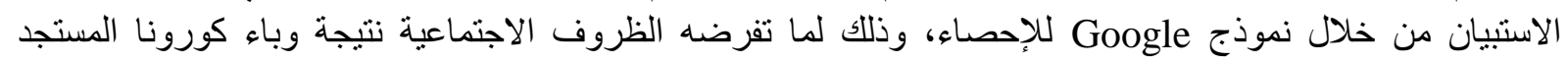

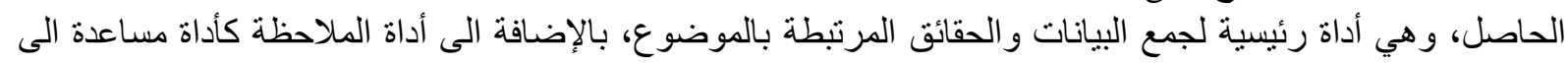

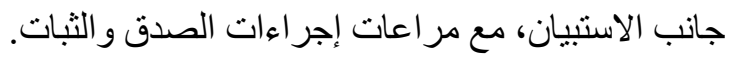

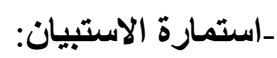

هي أسلوب جمع البيانات التي تستهدف استشارة الأفر اد المبحوثين بطريقة منهجية ومقننة لتقديم حقائق وآراء و أفكار

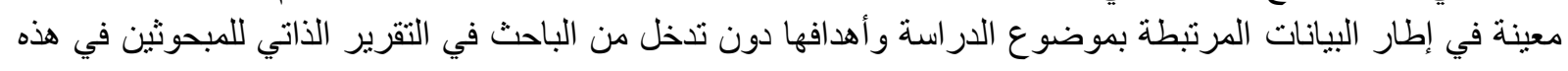

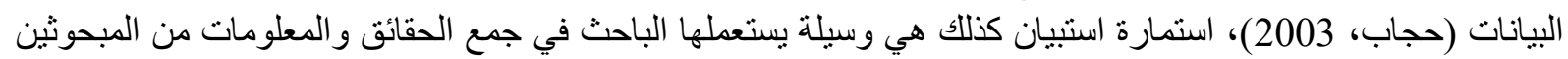

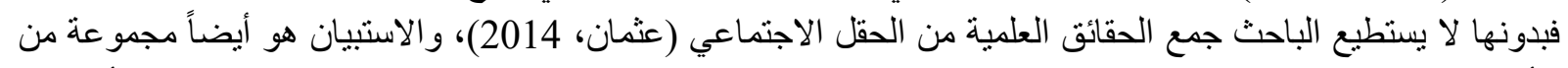

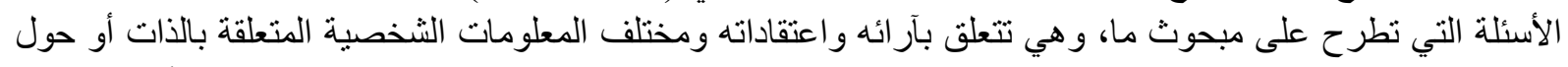

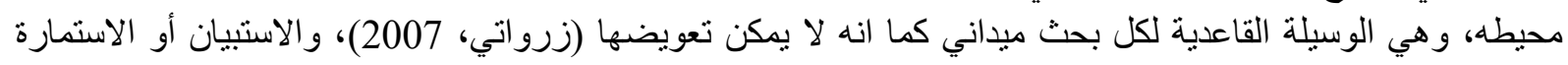

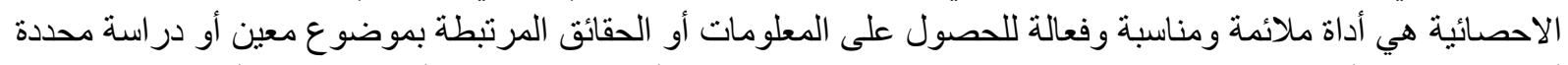

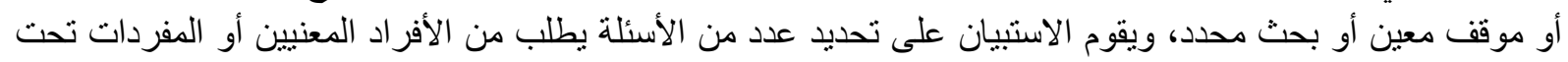

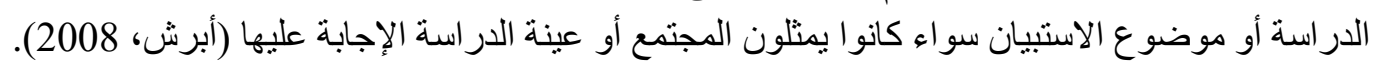

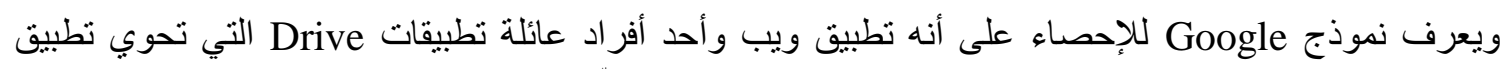

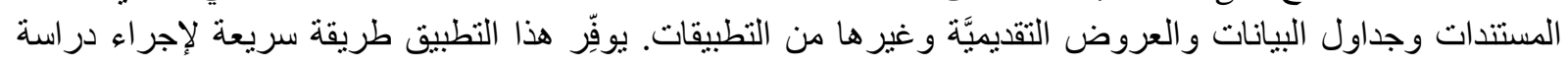



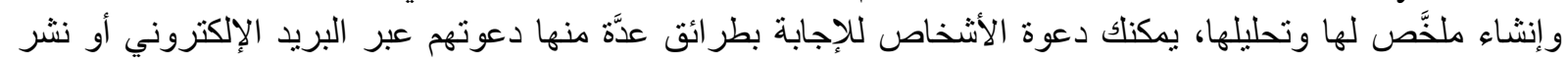

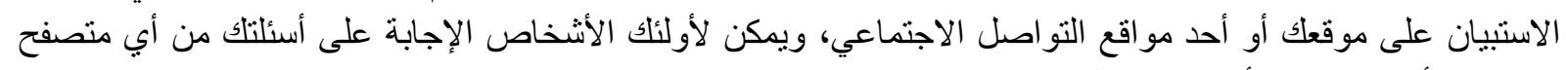

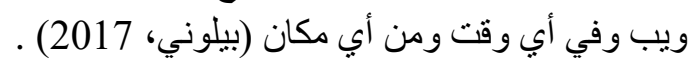

\section{ولقد شملت الاستمارة المصممة لهذا الغرض وال المحاور التالية:}

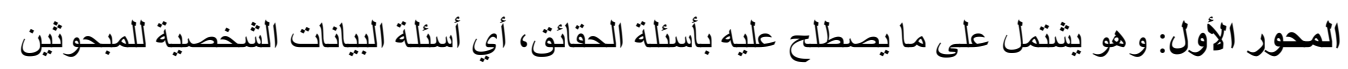

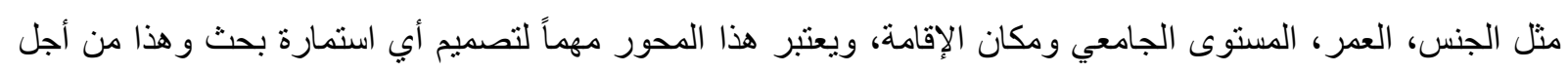

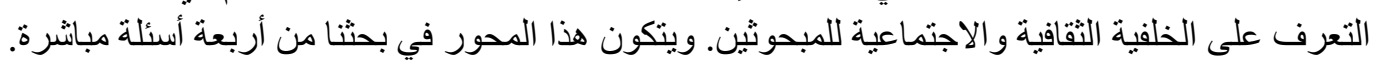

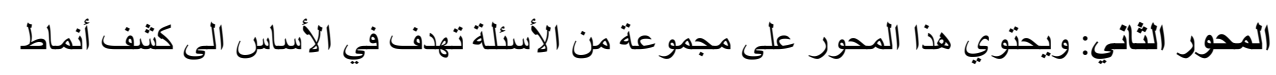

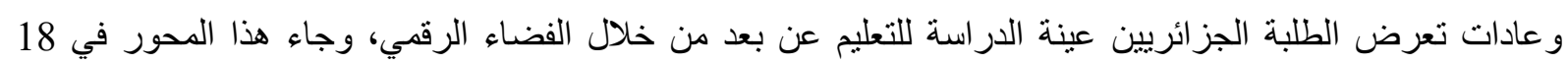

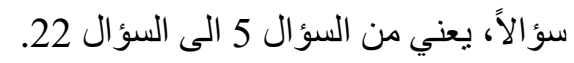


المحور الثالث: ويعتبر أهم محور في الاستبيان، لأنه يركز على التأثثرات التي تحدثها عملية التعليم عن بعد على القيم المعرفية لدى الطلبة الجز ائريين، ويشمل هذا المحور على 14 سؤالاً، يعني من السؤال 23 الى السؤ الى 36.

الإطار النظري للاراسة:

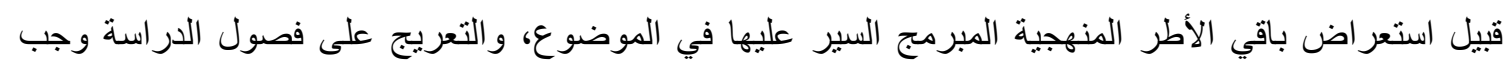

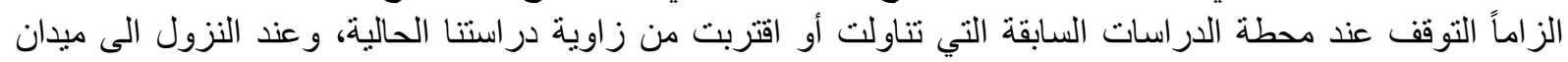

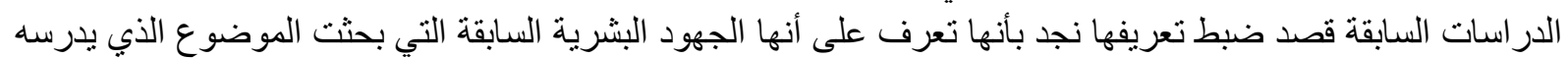

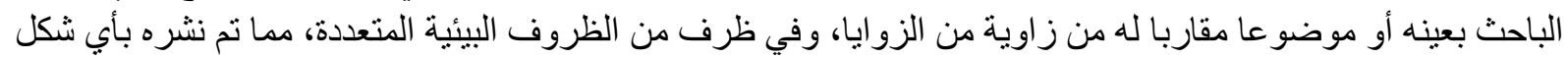

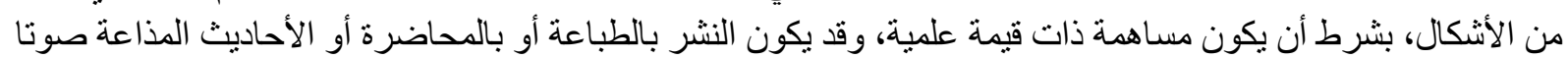

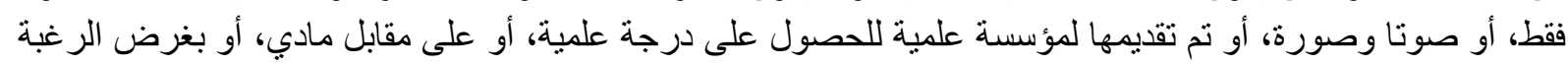

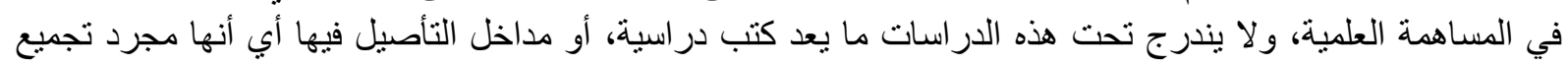

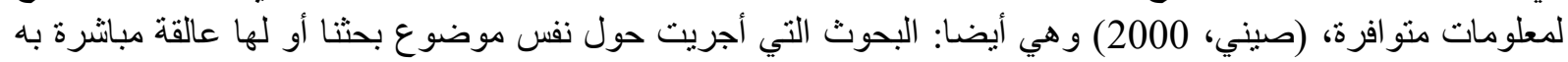

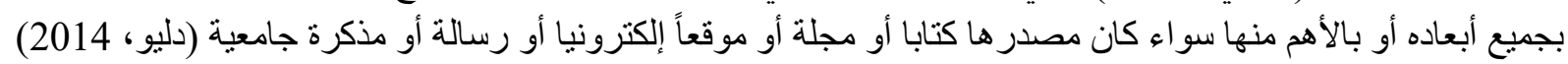

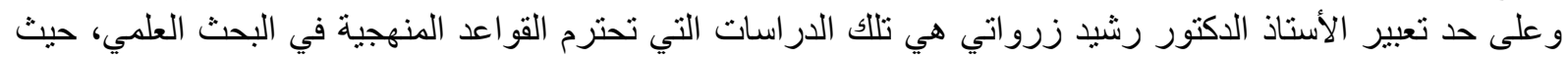

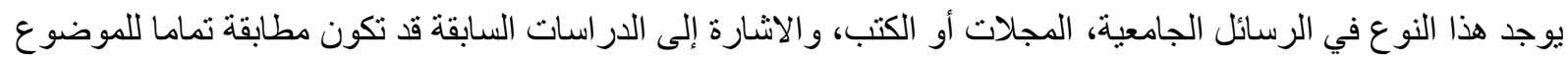

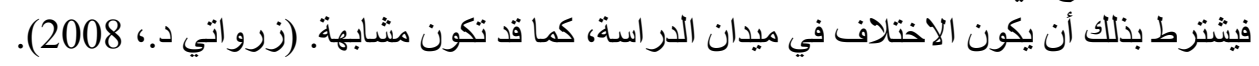

\section{قراعة في نظرية الحتمية القيمية في الإعلام لعبد الرحمن عزي -روئة نظرية تحليلية - (هادفي، 2021)}

هذه الدراسة تظهر وتبز أهميتها في مساهمتها في قراءة نظرية الحتمية القيمية في الاعلام ومعرفة أسس بنائها

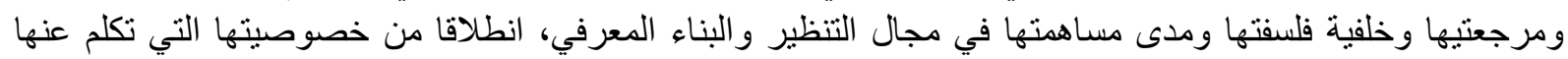

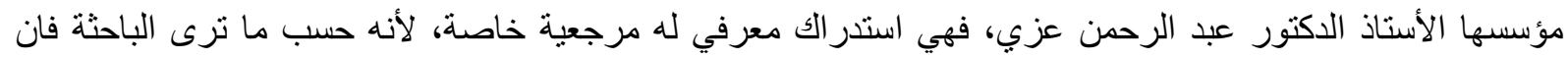

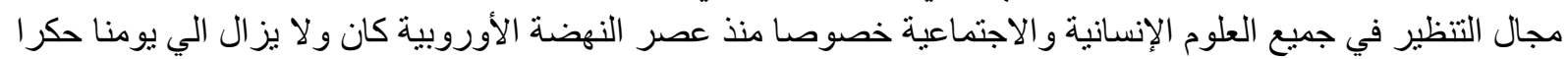

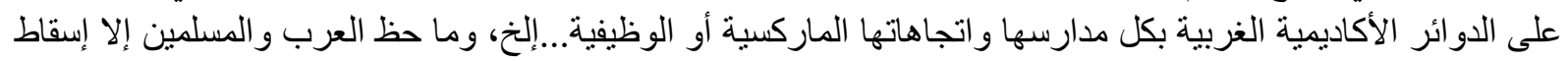

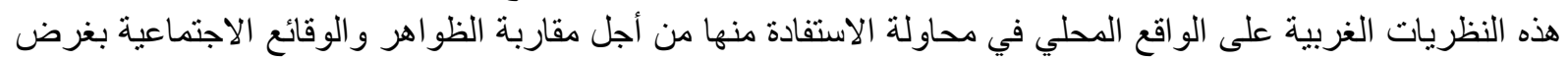

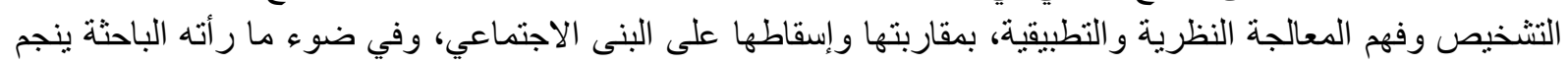

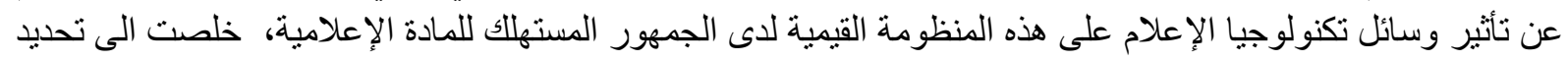

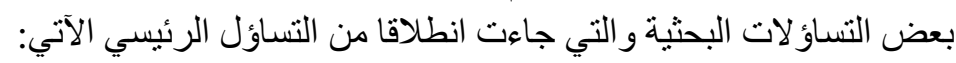
ما هي الأسس النظرية التي تقوم عليها الحتمية القيمية؟ والته ويتفرع عن هذا السؤال أسئلة أخرى وهي:

1 -ما هي الإضافة الجديدة التي أتت بها هذه النظرية؟ النه

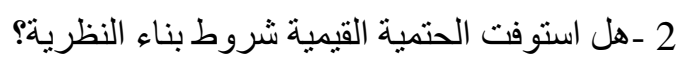

3 -هل يمكن تطبيق هذه النظرية في البحث السوسيو إعلامي؟

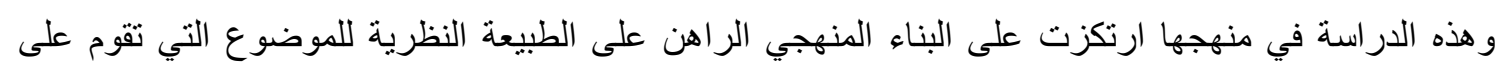

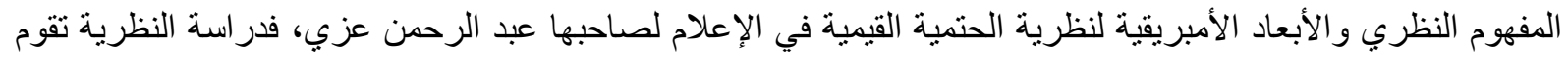
على قر اءة في مرجعية بناء نظرية الحتمية القيمية. وفي هذه الدراسة وبعد تحديد المحددات المرجعية الفكرية لنظرية الحتمية القيمية التي استتد فيها الأستاذ الدكتور

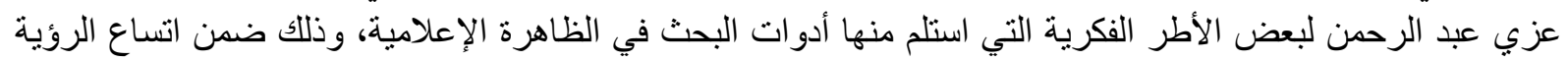

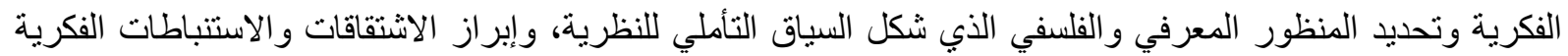
التي استلهم منها بعض المقو لات في بناء نظرينه.

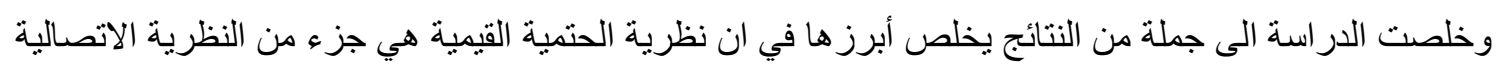

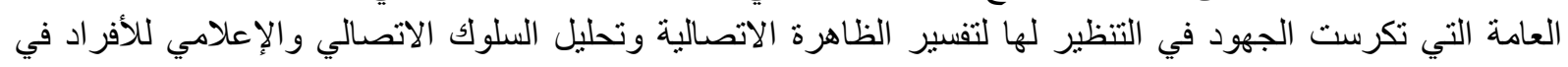


تفاعلاتهم اليومية مع وسائل الإعلام، كما ساهمت النظرية في تقديم بر اديغم تفسيري لعناصر و وأبعاد العملية الاتصالية، في

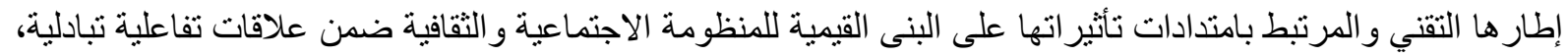

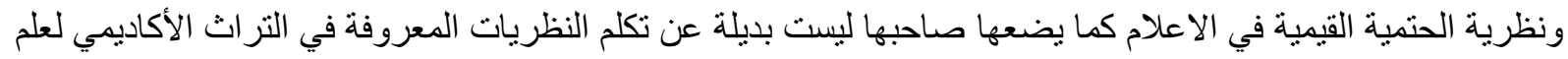

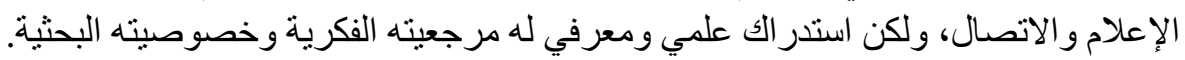

\section{كيف تقرأ وتفهم نظرية حتمية القيمة لوسائل الإعلام؟ نهج هيكلي دلالي(Nassir Bouali, 2021)}

هذه الدراسة من بين الدراسات القليلة التي طرحت نظرية الحتمية القيمية في الاعلام باللغة الإنجليزية، وقد عملنا

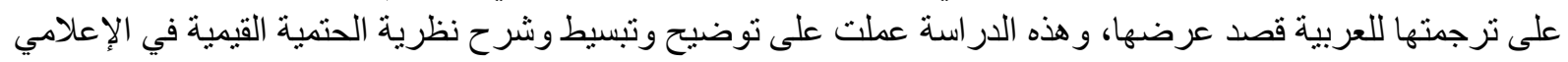

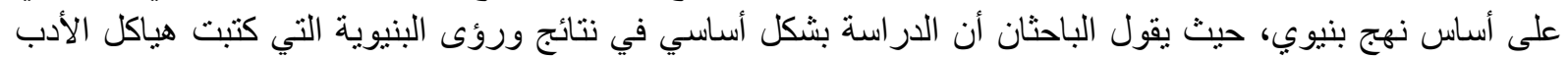

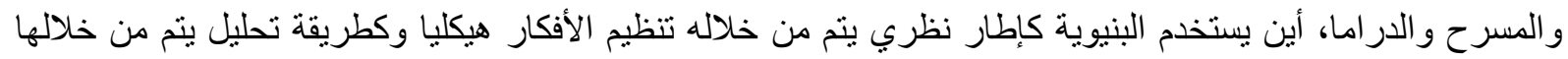

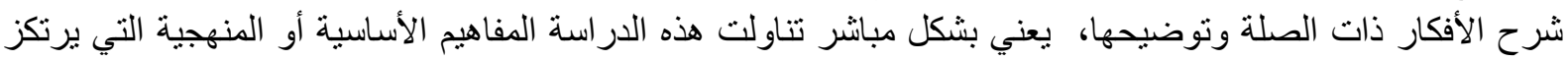

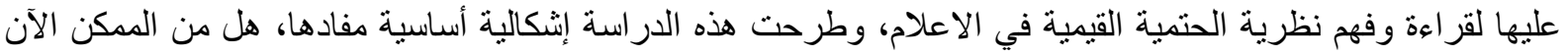

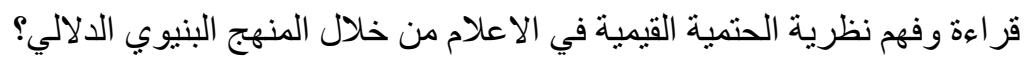

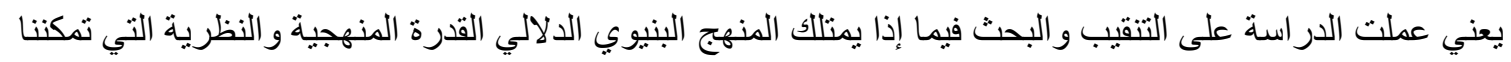

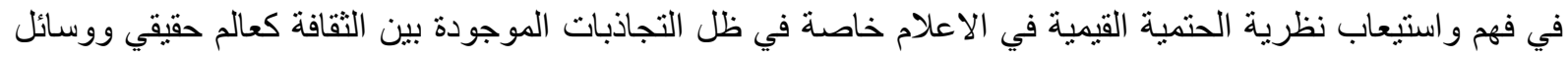

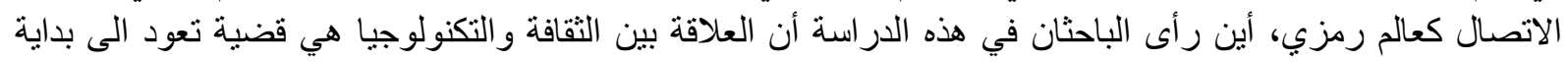

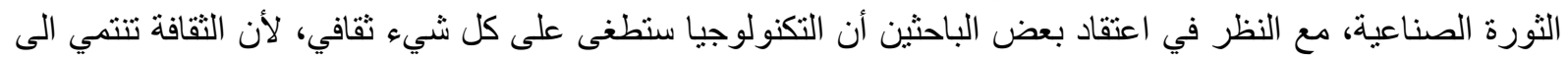

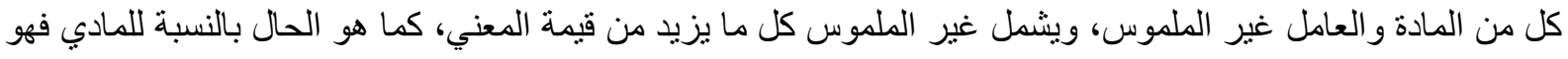

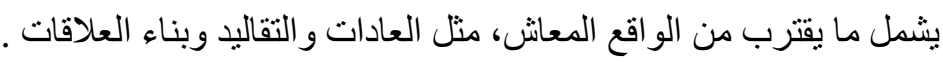
وخلصت هذه الدر اسة الى مجمو عة من النتائج نذكر أبرز ها و أهمها في التالي :



2-عزي و الدراسات البحثية للمهتمين بالنظرية التي بحثوا عنهيا.

3- يبدو من الصعب فهم العديد من المفاهيم والمصطلحات في النظرية ولكن بمجرد قراعتها بعناية يمكنك فهمها و آفاقها المستقبلية في البحث الإعلامي.

4 -وصفت هذه النظرية (VDT) لوسائل الإعلام في يوليو 2012 بأنها فكرة كبيرة على مدى المائة عام

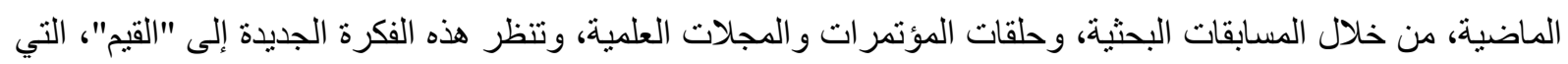



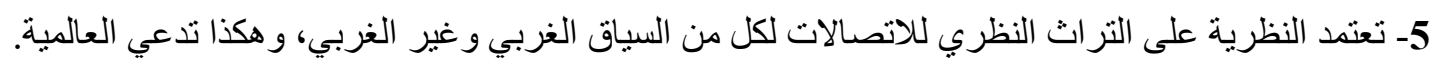

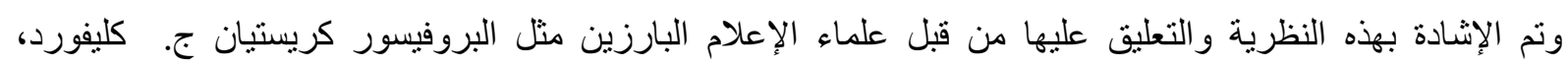
البروفيسور ماكس ماكومب، مؤلف جدول الأعمال نظرية الإعداد، و البروفيسور الئن إلم جريفين.

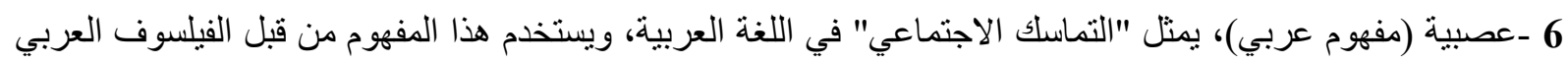

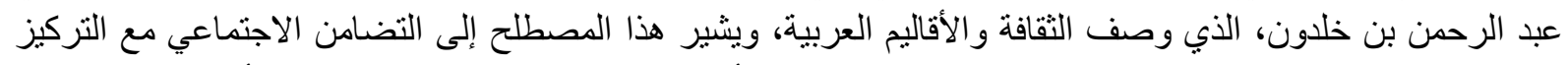



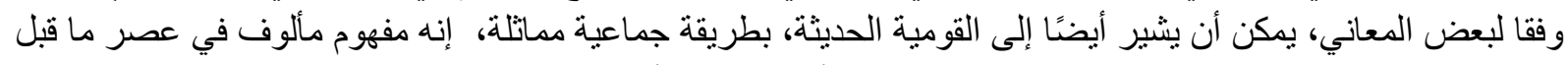

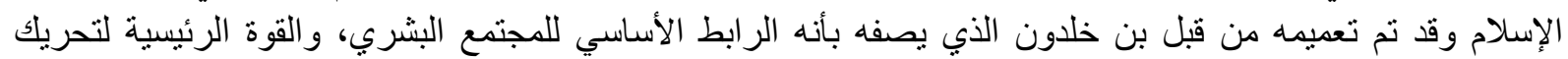

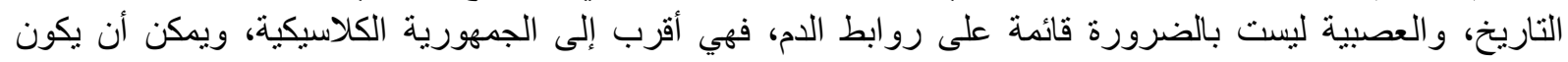

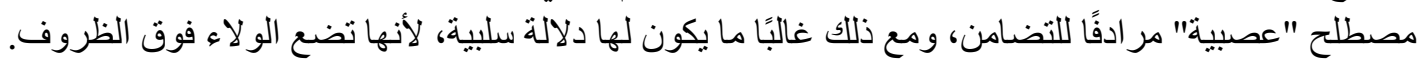


هي در اسة وصفية تحليلية لست محاضر ات سمعية بصرية ألقيت عبر منصة رواق، وهي من انجاز الدكتورة عائشة

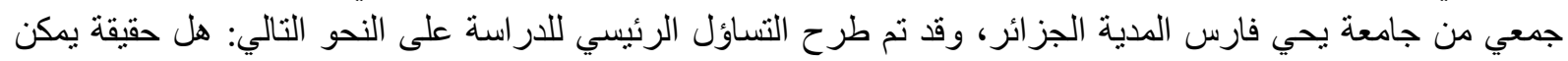

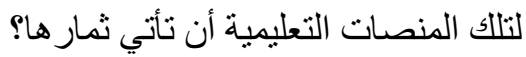

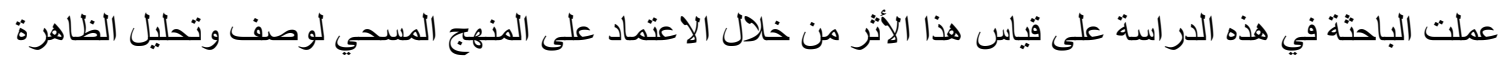

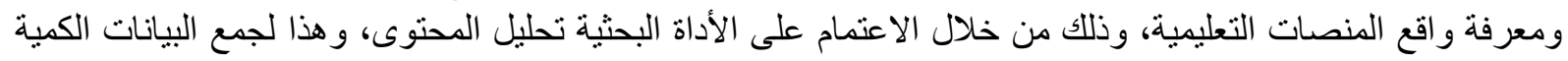

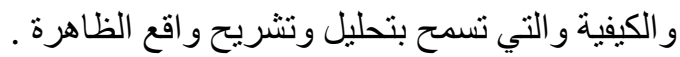

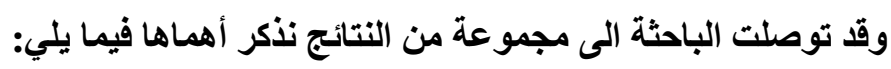

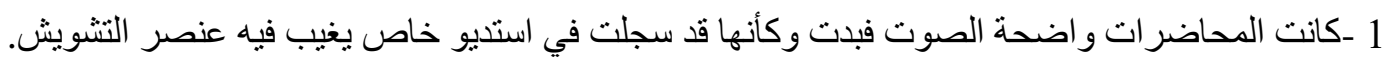

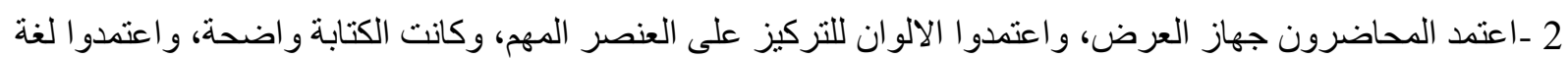
الجسد كذللك في إيصال المعلومة.

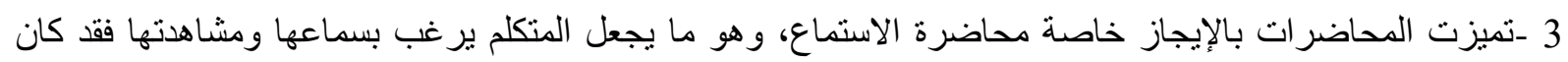

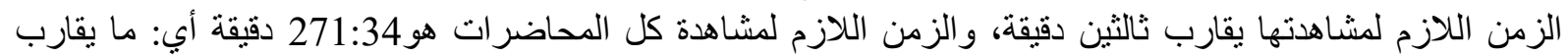
خمس ساعات لست محاضر اتلات 4 ـلم تتجاوز و لا محاضرة الساعة الو احدة فكل المحاضر ات كانت دون الساعة ونر اوح زمنها بين 30:19 د و 58:35 د.

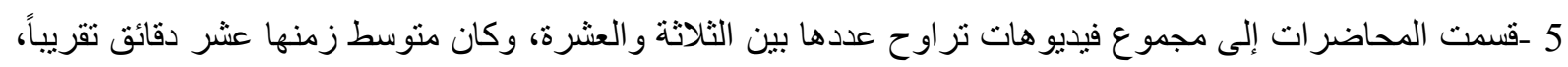

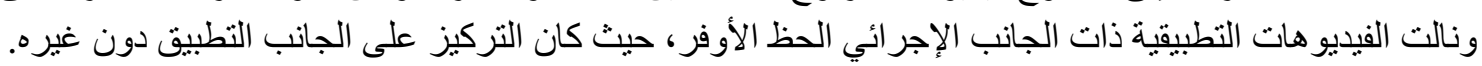



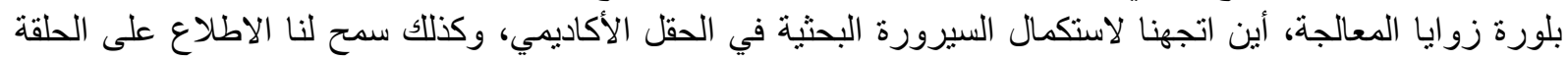

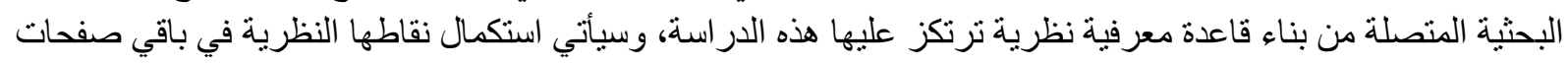

هذه الورقة البحثة.

\section{المقاربة النظرية لنظرية الحتمية القيمية في الاعلام:}

حسب قول الدكتور نصير بو علي فان الناظر والمتمعن في صميم وعمق نظرية الحتمية القيمية في الاعلام المنتسبة

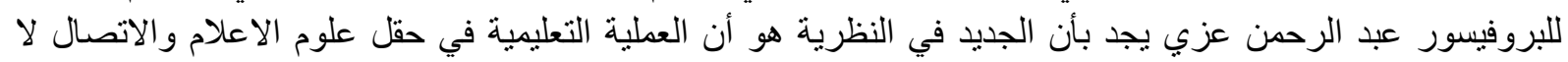

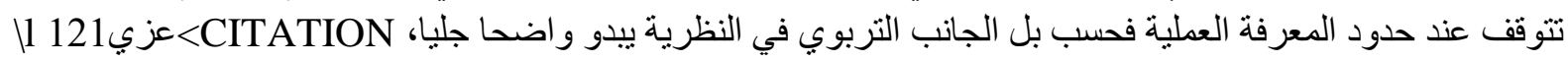

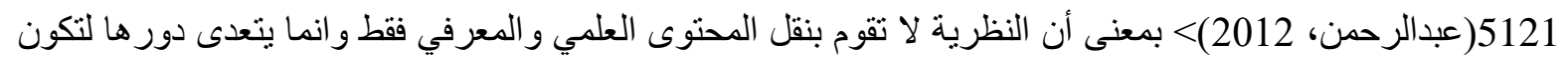

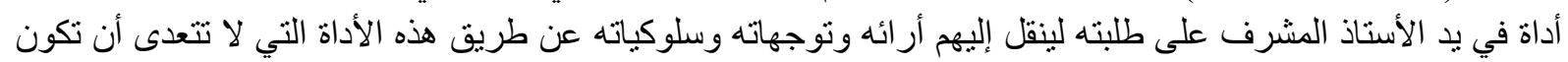



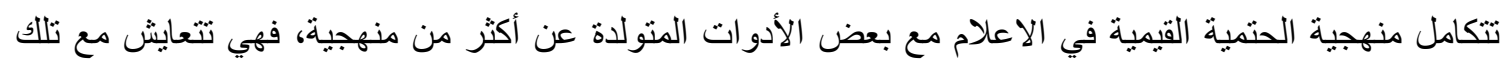

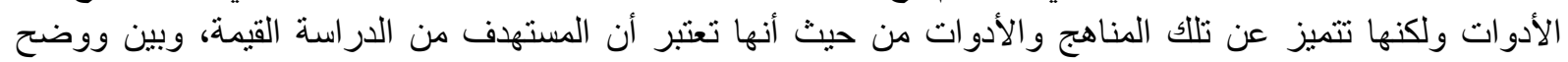

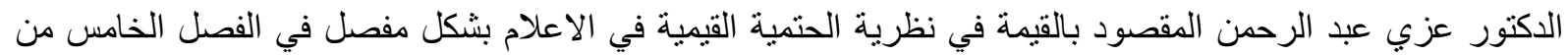

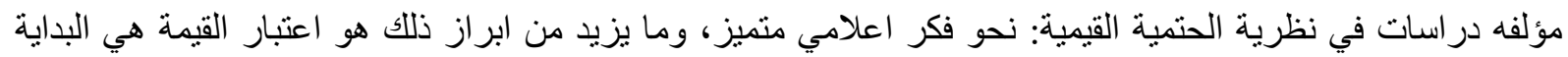

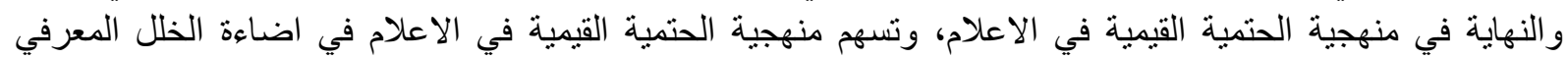

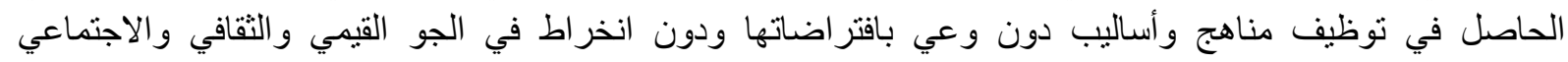

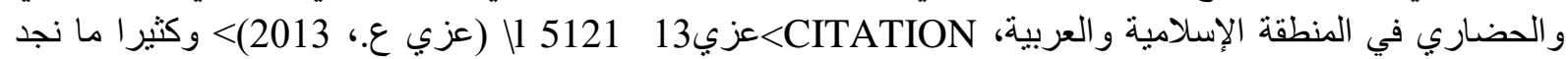

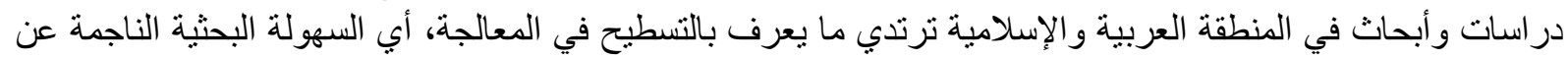
فقر فكري وتسيب أدو اتي ييتعد عن تقاليد البحث الأكاديمي و أخلاقيات المماري مرسة البحثية. 


\section{تعريف النظرية يشتمل على شرح ثلاثة مصطلحات يتوجب التوقف عندها وشرحها وهي على النحو التالي:}

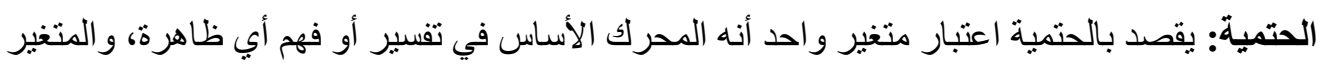

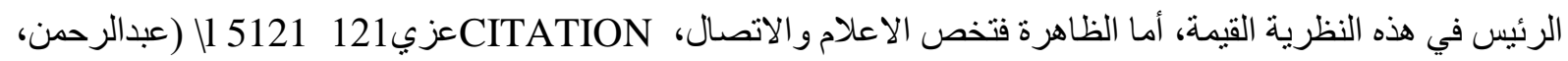
2012) يعني أي ظاهرة إعلامية كانت لا يمكن أن يفسر أو يفهم الا من حيث قربه أو بعده عن القيمة، وتعتبر باقي المتغيرات مكملة أي تابعة.

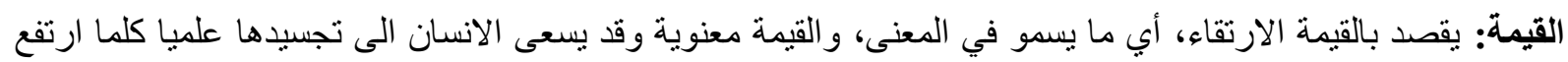

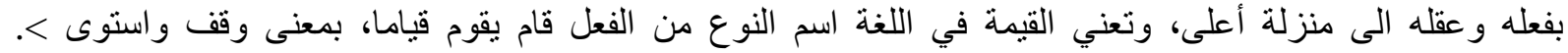
CITATION



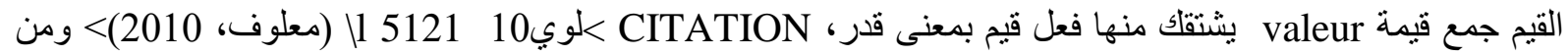

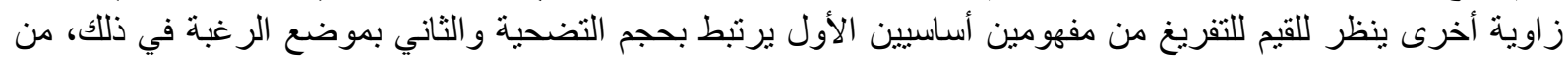

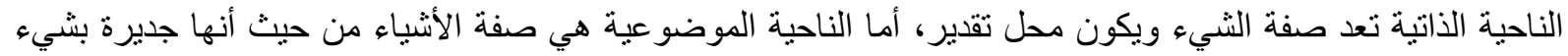

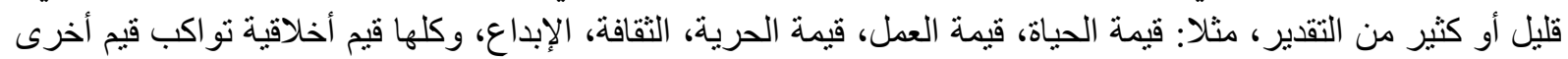

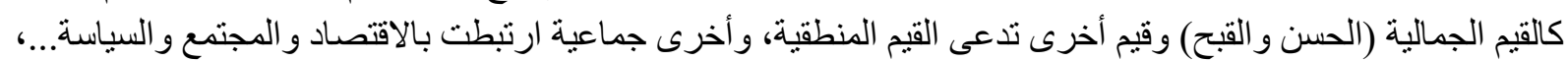
و الرغبة في الأصل تحيل إلى منل عليا غير أنها ارتبطت مع الحاجة وبالتالي بعامل الإنتاج و السوق، CITATION>

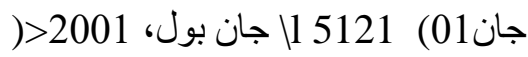

في الاعلام: يقصد بذلك رسالة الاعلام بوسائله التقليدية (الصحف، المجلات، الإذاعة، التلفزيون...)

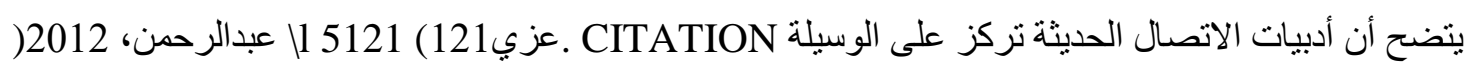



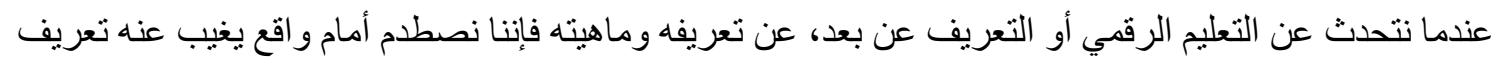

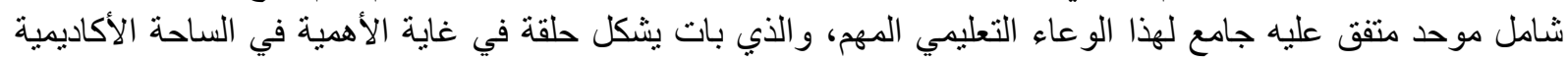

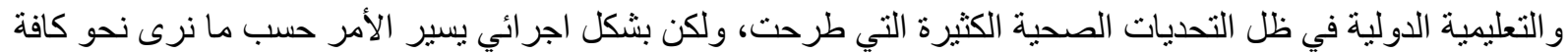

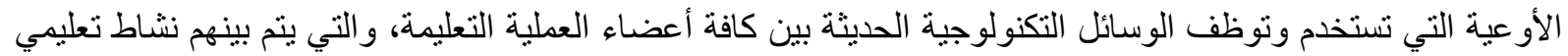
تو اصلي مباشر، يثري الملف المطروح للتعلم، ومع ذللك يمكن أن نجذب من بطون العلوم هذه الاختلافات التعريفية ونشير لئير

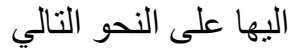

يعرف التعليم الرقمي على إنه عبارة عن استخدام الوسائل الإلكترونية والتي تهدف إلى الاتصال بين كل من المعلم

و المتعلمين بل نجد إنها تزيد الاتصال الإلكتروني بين المؤسسة التعليمية ككل. (الجريوي، 2014)

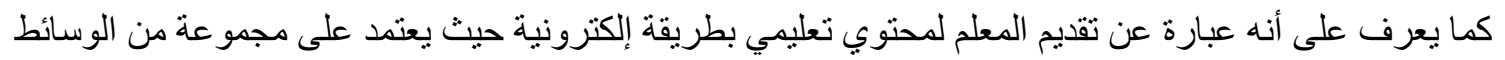

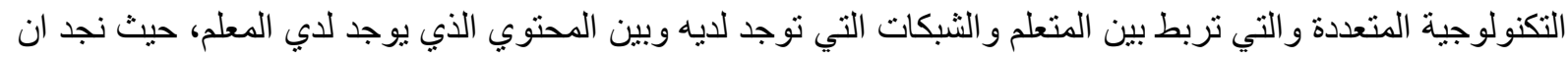

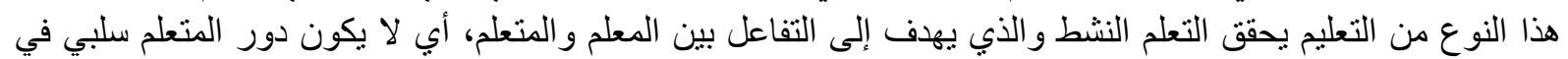

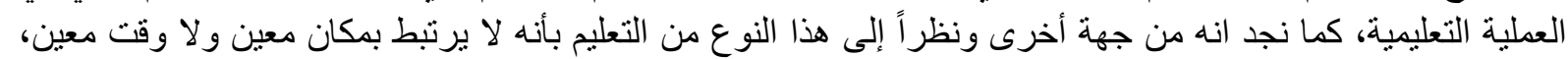
و إنما نجد انه بر اعي ما يعرف بمبدأ الفروق الفردية. (بوزيفي، 2016)

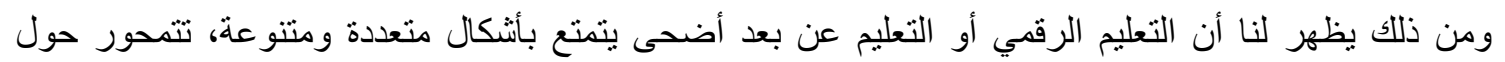

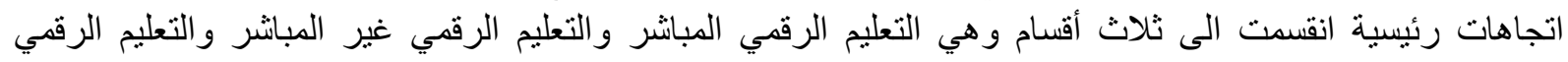




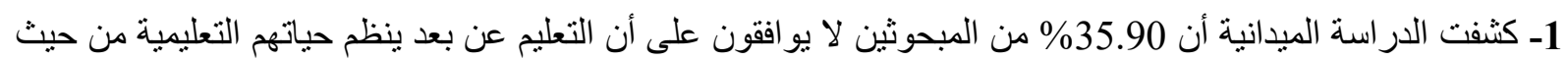

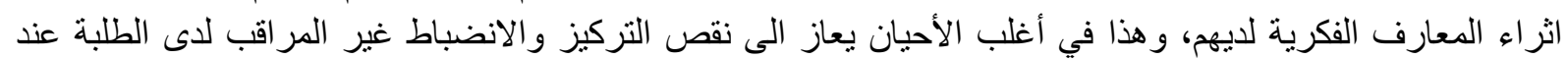

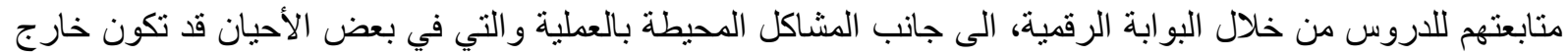

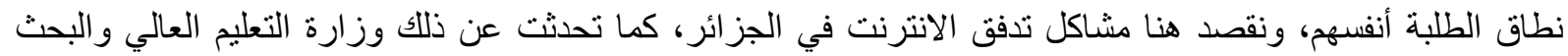

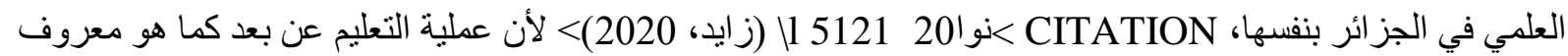

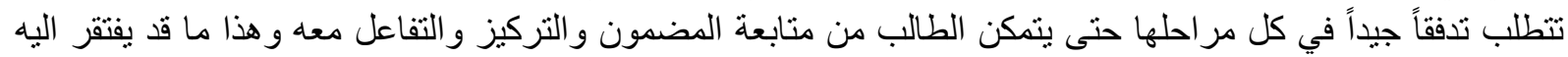

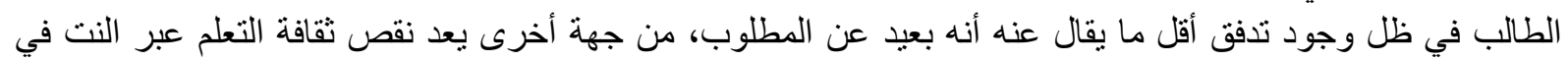

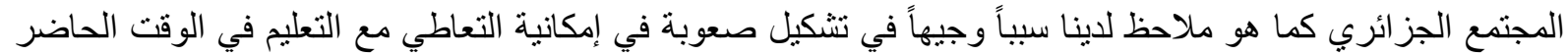

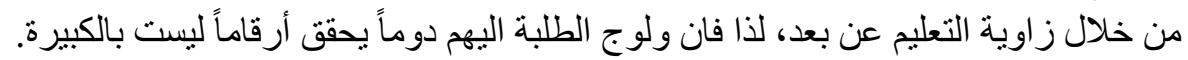

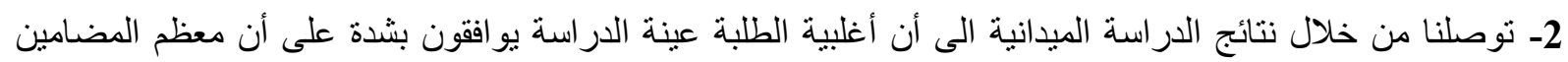

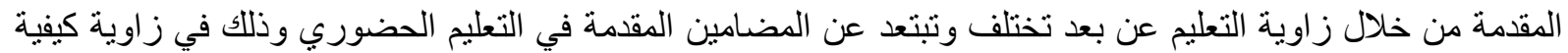

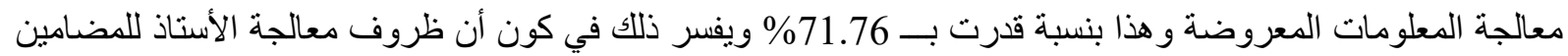

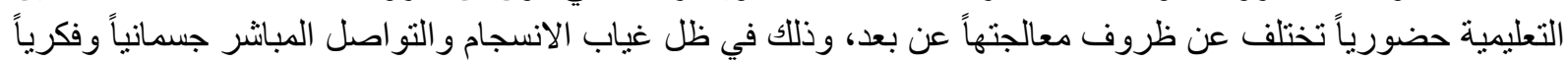

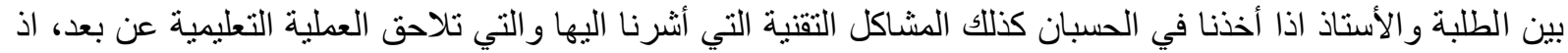



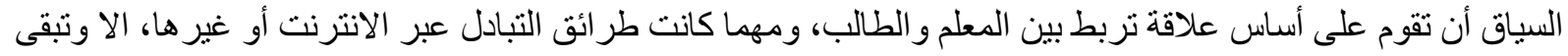

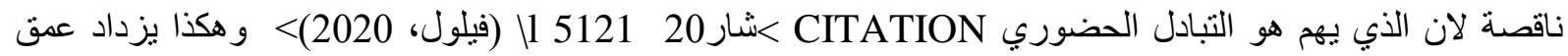
الفجوة التي نلاحظها اليوم بين الطلبة والأساتذة خاصة في الجامعات الجزائرية أين تحولت في بعض الأحيان الى شبه

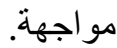

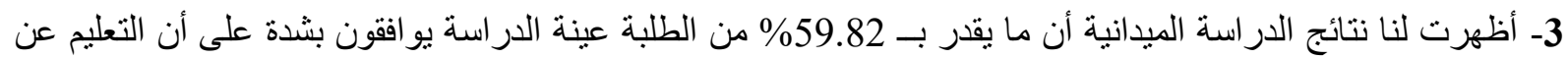

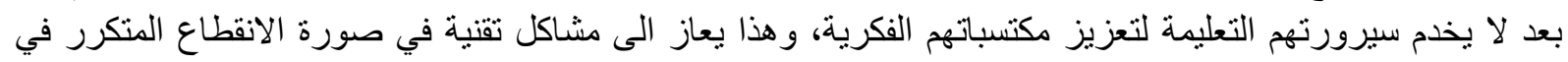

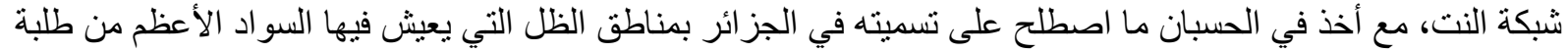

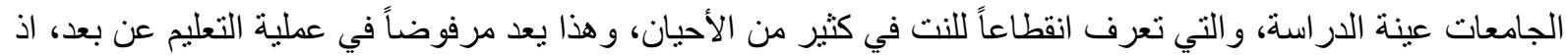

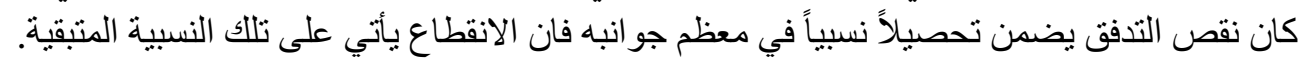

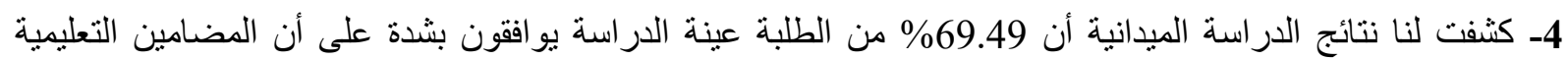

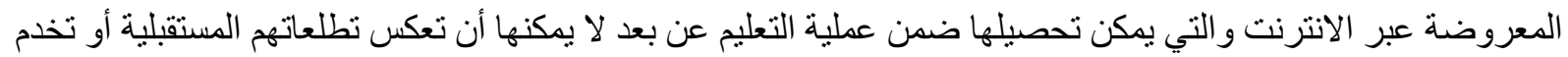

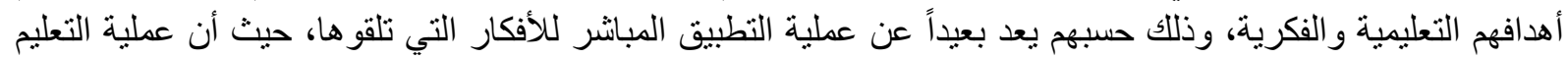


أكثر منه في التخصصات الاجتماعية والإنسانية.

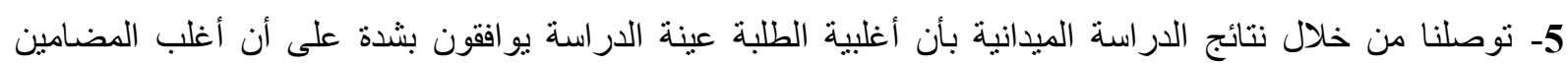

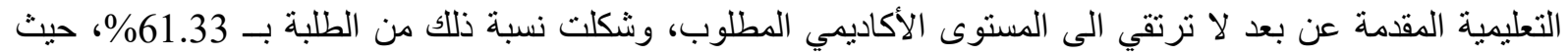

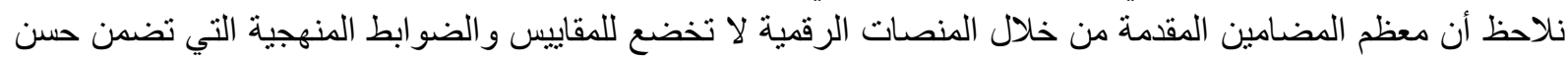

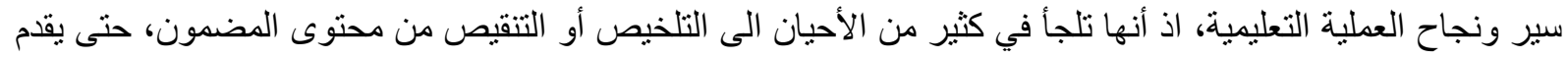

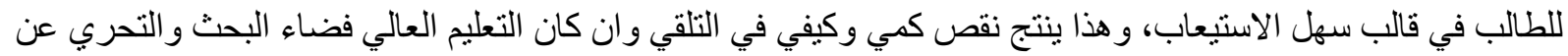

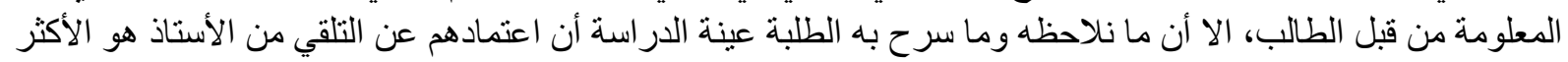

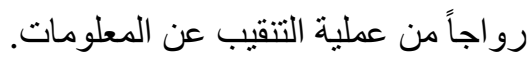

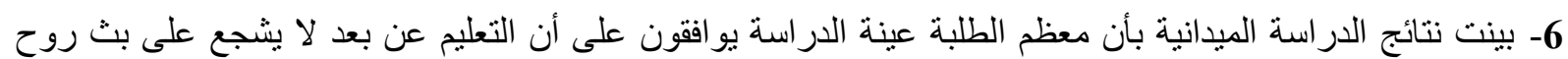

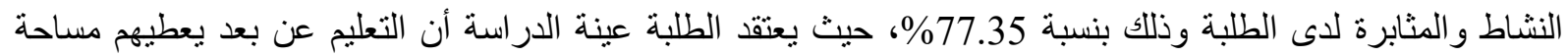
أوسع للراحة و البعد عن مقاعد الدراسة اذ أخذنا في الحسبان ظروف التنقل وما تفرضه من ضغوطات ملنة مادية ومعنوية 
للطلبة، لذا فان عملية التعليم عن بعد التي تقصي كل ذللك وتسمح للطالب من متابعة نشاطه التعليمي من المكان الذي كان

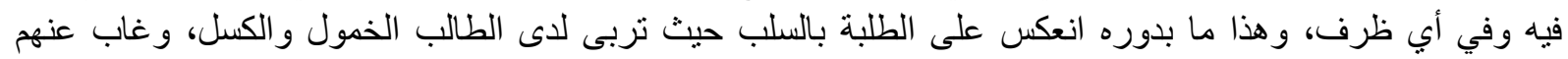
الحيوية و النشاط الذي كانت تفرضه وضه الجامعة ومحيطها المنضبط بالوفي بالوقت و المكان.

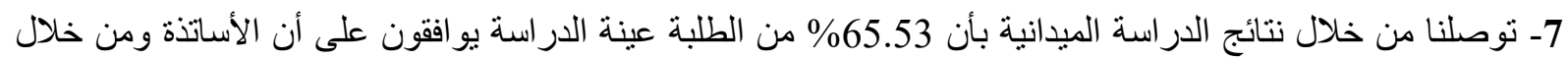

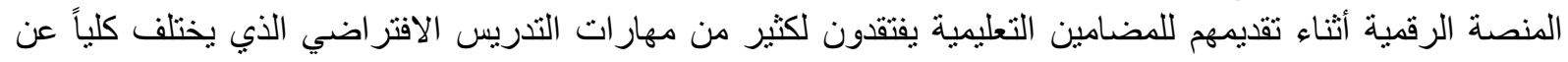

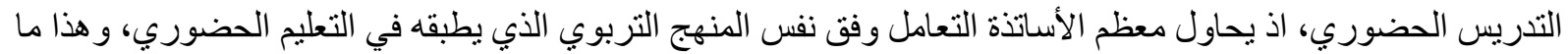

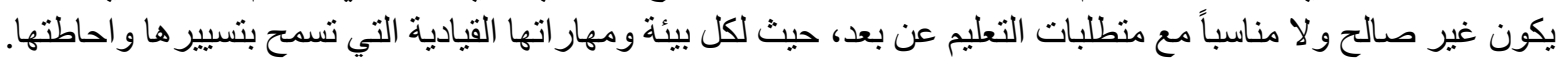

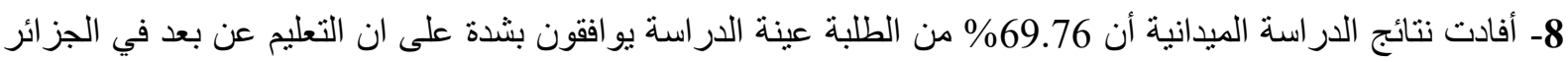

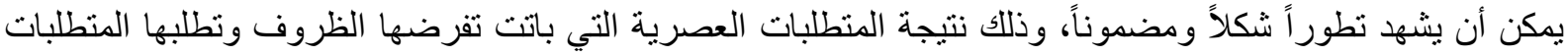

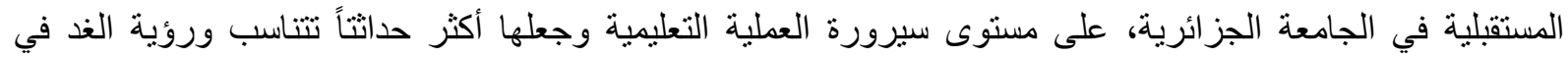

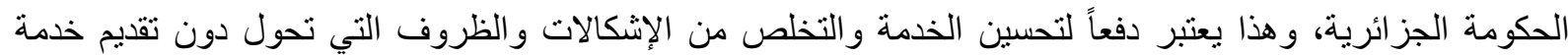

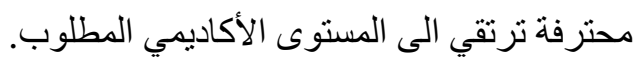

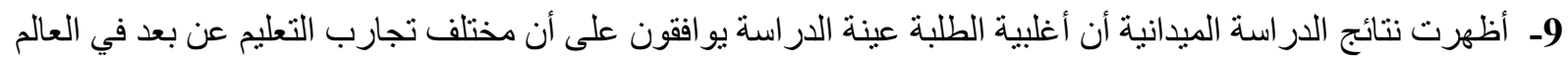

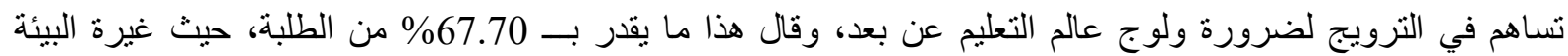

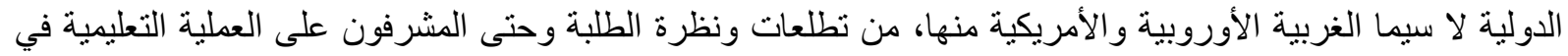

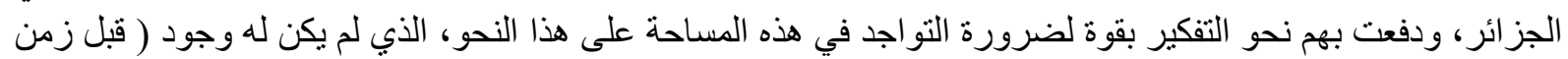
وباء كورونا المستجد ) وذهبت الحكومة الجزائرية اليه نتيجة الضغوطات الاجتماعية المفروضة من الوباء وتم انشاء

منصات

10- اتضح لنا من خلال نتائج الدر اسة الميدانية أن نسبة 82.53\% من الطلبة عينة الدراسة يو افقون على أن المضامين

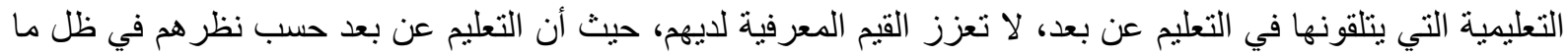

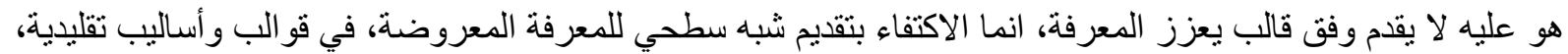

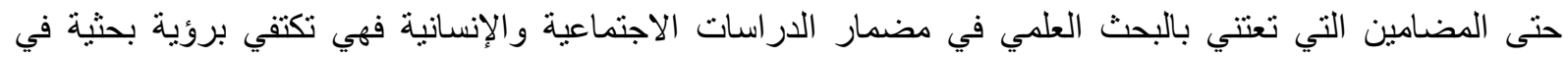
مساحات كلاسيكية، و هذا ما نلاحظه نحن أثناء التنقيب أو تحليل الدروس والثالئ المضامين التي يقدمها الأساتذة عن بعد فإنها

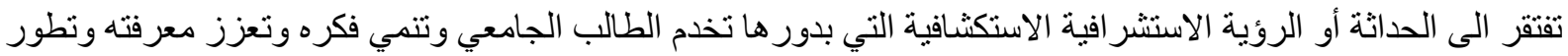
أسلوبه .

11- اتضح لنا من خلال نتائج الدر اسة الميدانية أن 74.66\% من الطلبة عينة الدر اسة يو افقون بشدة على الاتجاه القائل بأن النان

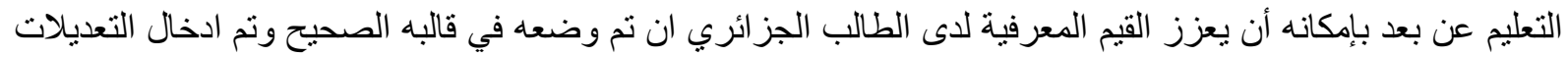

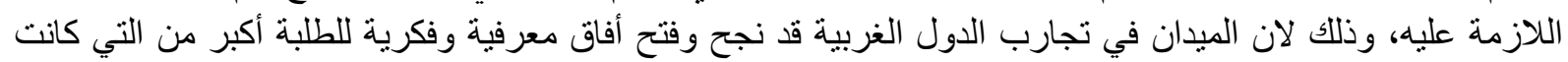

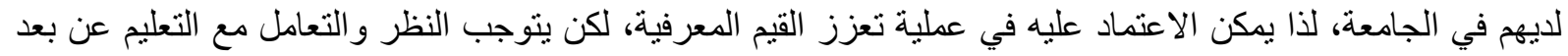

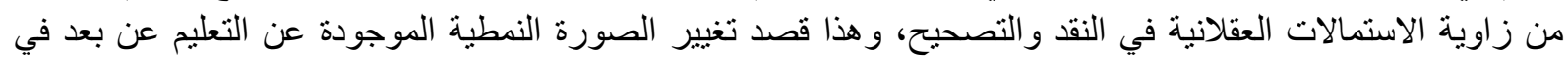

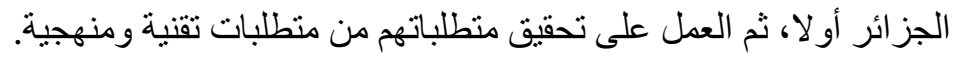

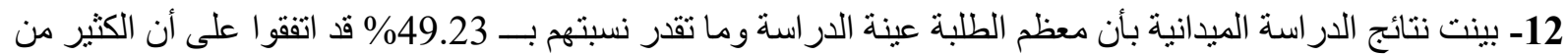

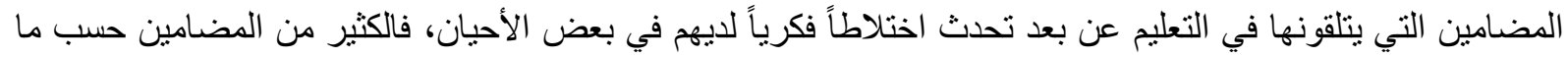



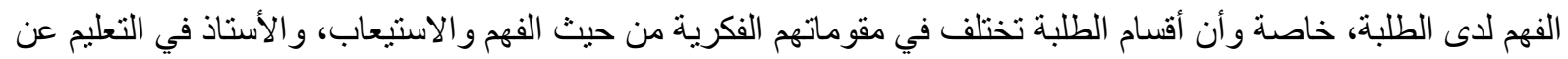
بعد يصعب عليه فهم و ادر الك ذلك بما ان الاتصال بينه وبين الطالب في بعض الأحيان غير مباشر كما أوضحنا.

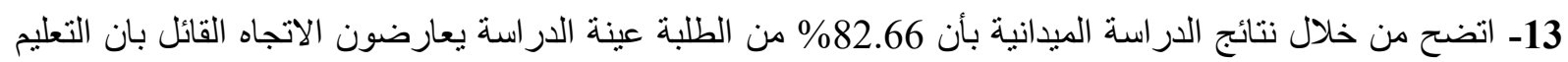



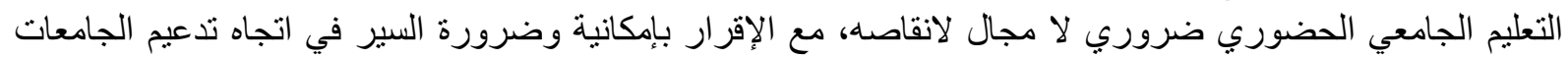

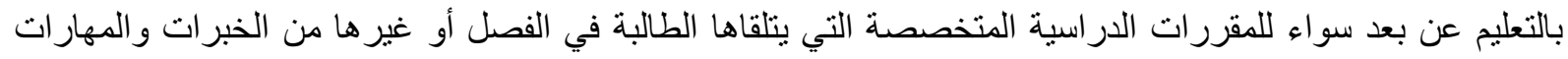

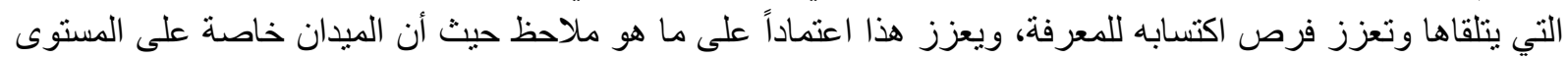

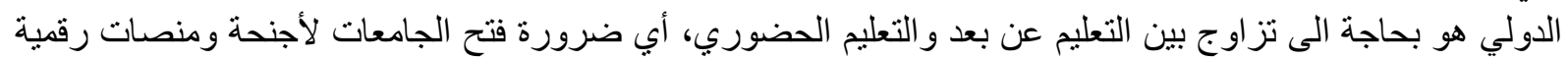


تقدم خدمات التعليم عن بعد، بما ان سوق العمل اليوم بات بتطلب جهد علمي ونقافي كبير لفهم معانيه ومفرداته وخطة

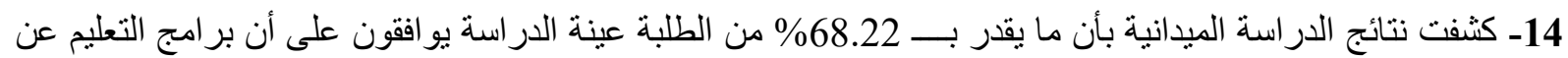

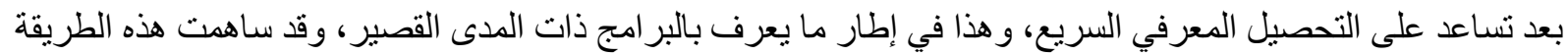

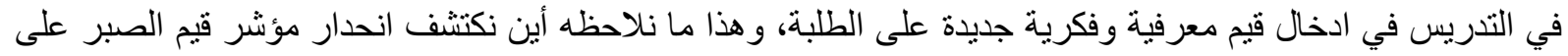

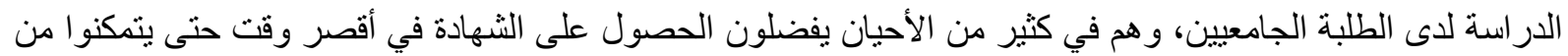

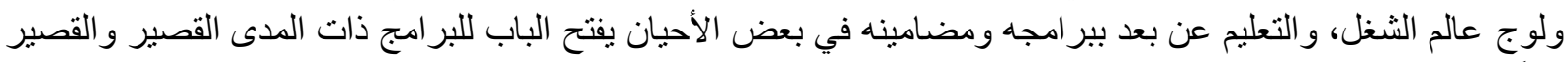

15- كثفت نتائج الدراسة الميدانية على أن أغلبية الطلبة عينة الدراسة يوافقون بدرجات متفاوتة على استخدام القيم المعرفية الاتية ضمن التعليم عن بعد في الفضاءات الرقمية، قيم المعرفة الضمنية بنسبة 75.49\% وقية النيم المعرفة الصريحة

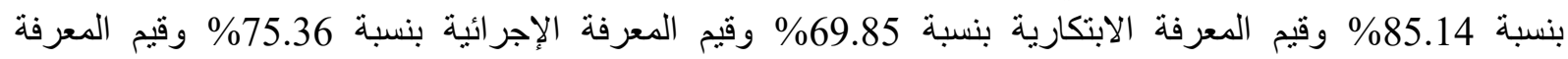

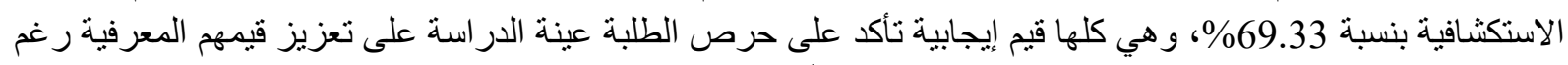

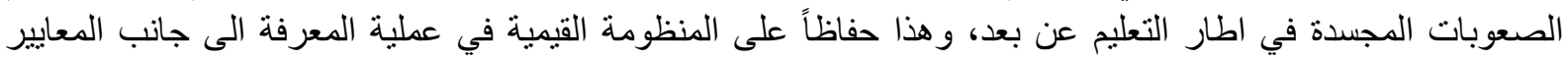

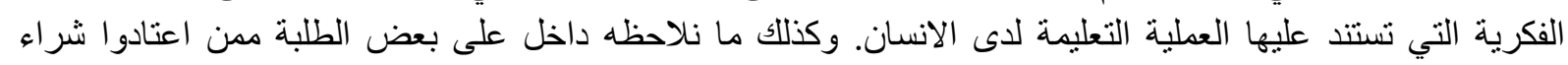
المعرفة عن بعد من خلال المنصات الرقيمة و الجامعات الالكترونية ولنية.

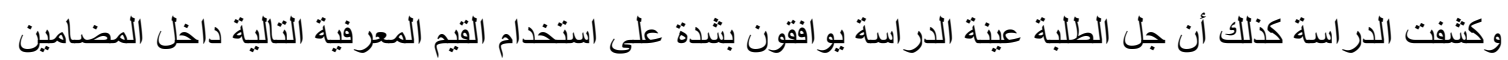

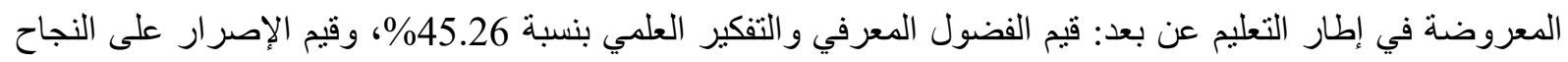

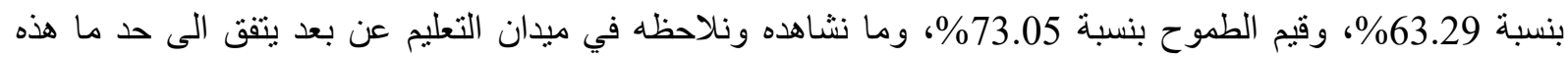
النتائج، حيث نلاحظ الى جانب هذه القيم استخدام قيم الثقة في النفس وقيم الابداع وقيم الإنتاجية الفكرية.

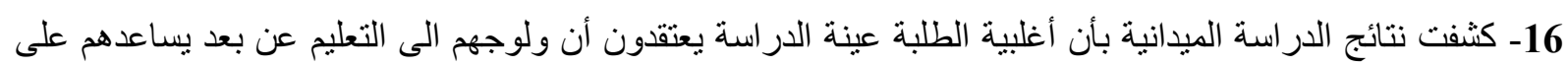

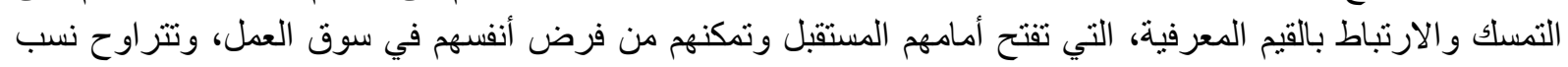

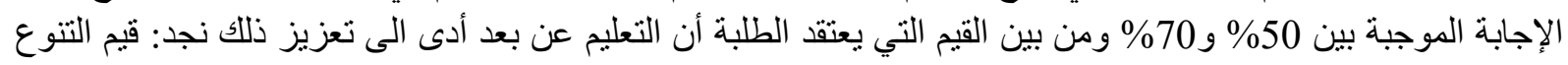

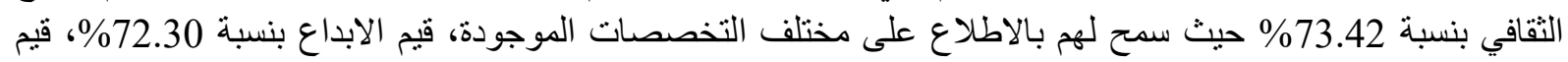

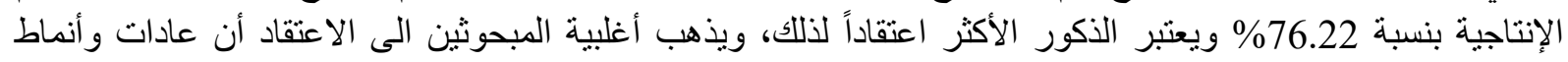

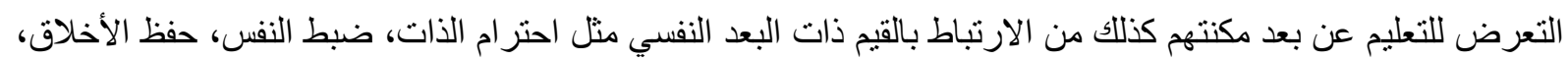
أكثر من الأبعاد القيمية الأخرى.

كما ذهب الطلبة عينة الدراسة للاعتقاد بان التعليم عن بعد يساعدهم في الارتباط بالقيم ذات البعات البعد الاجتماعي مثل الاحترام

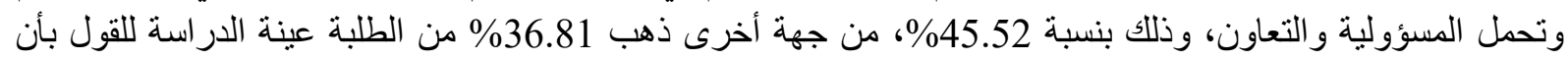

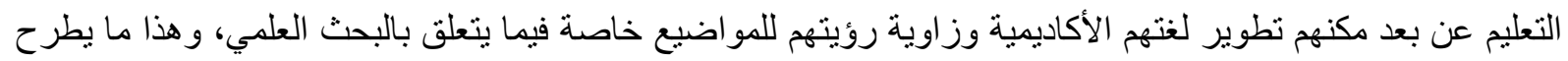


الطلبة الجز ائريين، و هذا ما قال به عاه 35.28\% من الطلبة عينة الدر اسية.

خاتمة

تعتبر القيم من بين أبرز و أهم و أكثر الملفات التي تحتاج للبحث و التتقيب في الساحة الاجتماعية و الإنسانية، خاصة

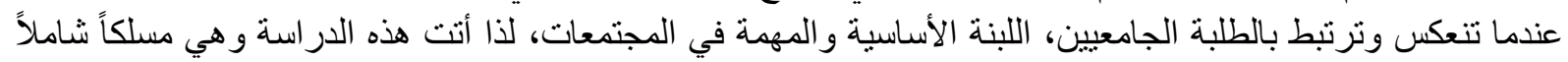

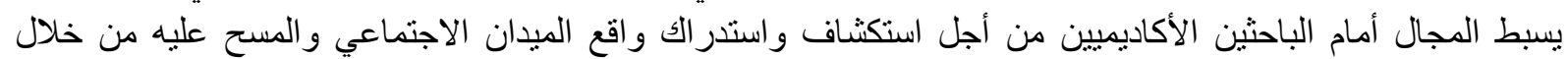

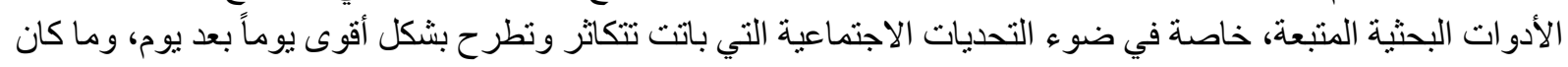

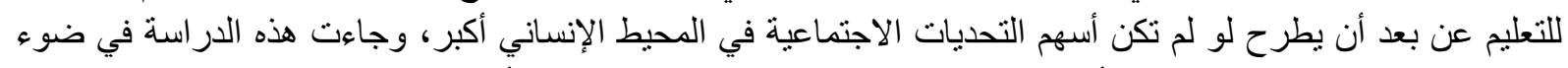

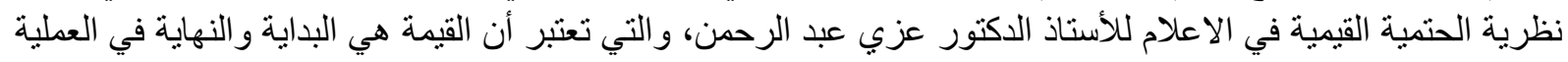

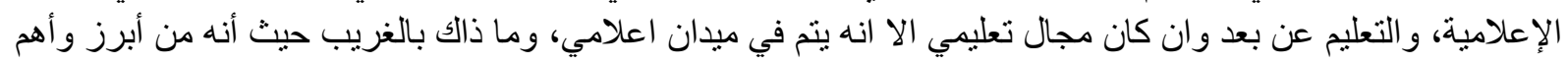

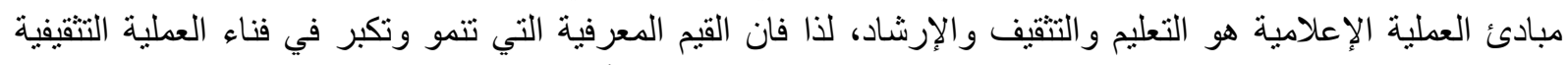

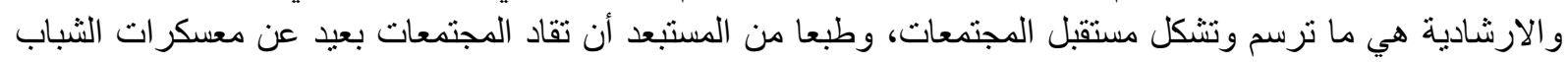






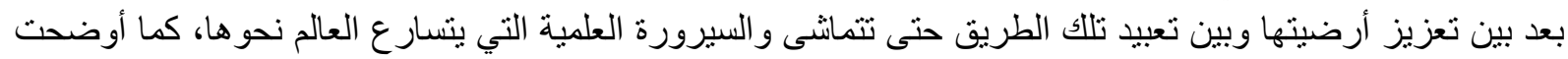

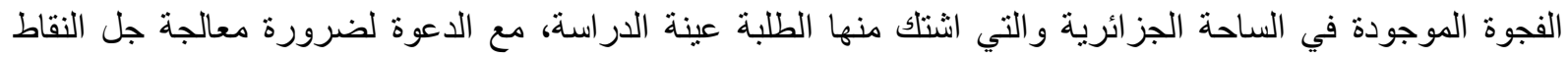

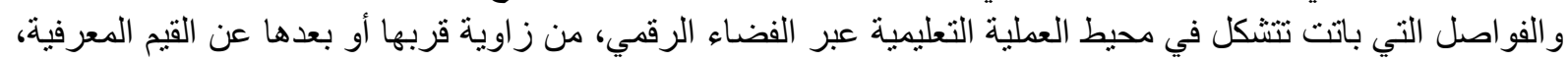

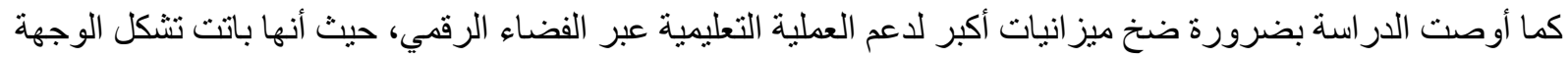
مستقبلاً نحو العالم الأكاديمي. 
سهام بنت سلمان الجريوي. (2014). استخدام مستودعات الكائنات الرقمية التعليمية في الممارسات التندريسية لأعضاء

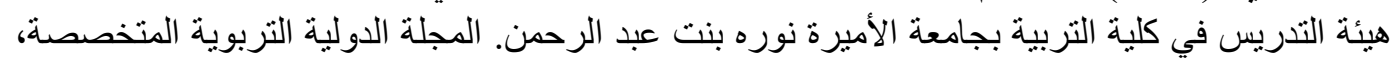

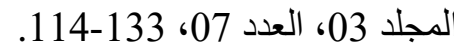

ابر اهيم أبرش. (2008). المنهج العلمي وتطبيقاته في العلوم الاجتماعية : ulhk العندة الثروق للنشر و التوزيع / نسخة. الكترونية، موقع مكتبة عين الجامعة.

أحمد بن مرسلي. (2010). مناهج البحث العلمي في علوم الاعلام والاتصال. الجزائر العاصمة: ديوان المطبوعات الجامعية، الطبعة 4 / نسخة الكترونية، موقع.

أحمد بنمرسلي. (2013). الاسس العلمية لبحوث الاعلام و الاتصال. الجزائر العاصمة: دار الونة الورسم للنشر و التوزيع.

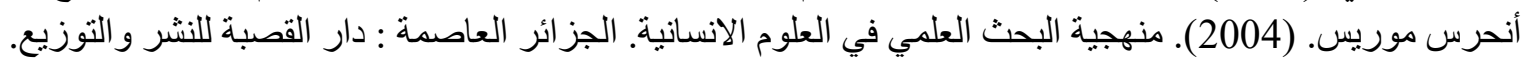

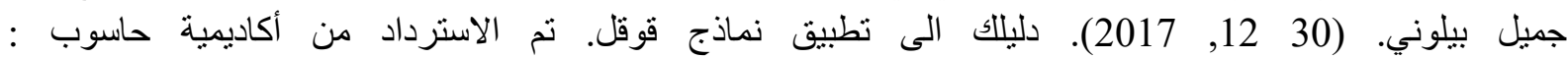
https://cutt.us/dbZAB

د.رشيد زرواتي. (2008). التدريبات على منهجية البحث العلمي في العلوم الاجتماعية. الجزائر: ديوان المطبوعات الجامعية.

ذو الفقار شيماء. (2009). مناهج البحث والاستخدامات الاحصائية في الدراسات الاعلامية. القاهرة : الدار المصرية

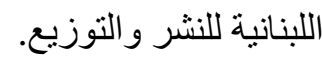

رزقير، ترجمة عادل علوا جان بول. (2001). فلسفة القيم. بيروت: دار عويدات للنشر و التوزيع، نسخة الكترونية ، موقع

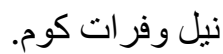

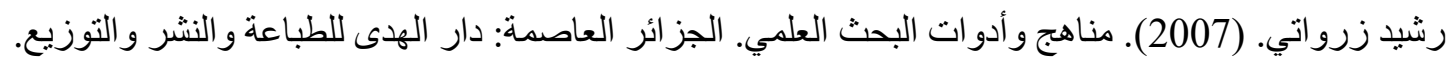

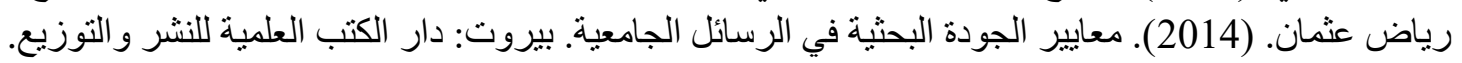

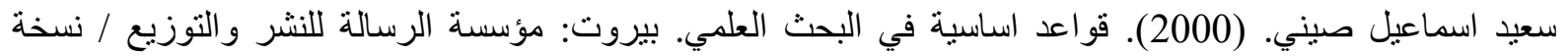
الكترونية موع النور.

سمية هادفي. (07, 2021). قراءة في نظرية الحتمية القيمية في الإعلام لعبد الرحمن عزي -رؤية نظرية تحليلية -..

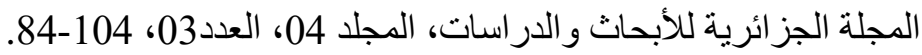

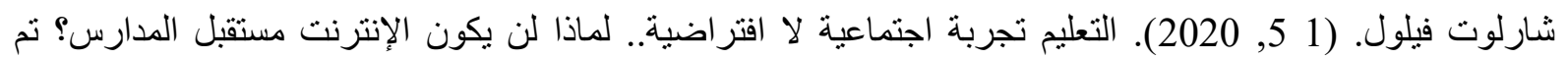
الاسترداد من الجزيرة نت https://cutt.us/VqGc9)

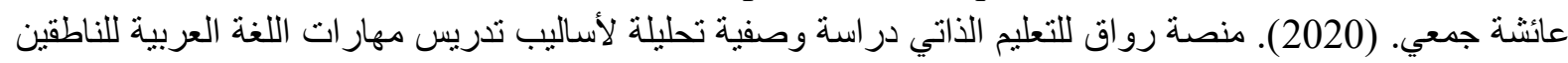

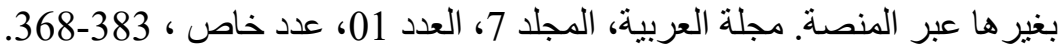

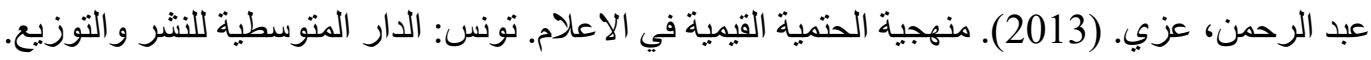

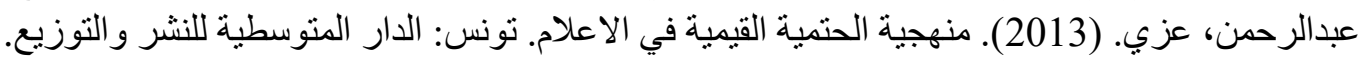

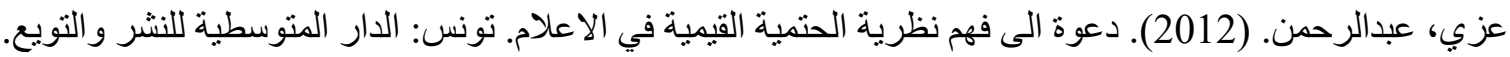

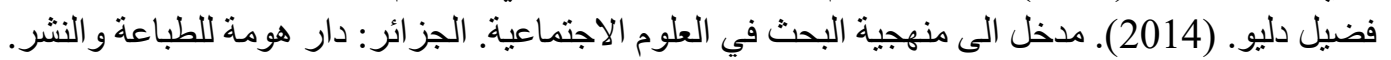
لويس معلوف. (2010). المنجد في اللغة و العلوم. بيروت: المطبعة الكاثوليكية، نسخة الكترونية، المكتبة العالمية الوقفية الالكترونية.

محمد الهادي. (1995). أساليب اعداد ونوثيق البحوث العلمية. القاهرة: الكتب الأكاديمية للنشر و التوزيع. محمد شفيق. (2000). البحث العلمي (الخطوات المنهجية لاعداد البحوث الاجتماعية). الاسكندرية: المكتبة الجامعية للنشر النشر

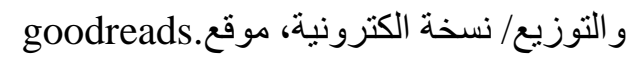

محمد عبد الحميد. (1993). دراسات الجمهور في بحوث الاعلام. الاسكندرية: دار عالم الكتب للنشر و الونوزيع / نسخة الكترونية، موفع مكتبة النور.

محمد منير حجاب. (2003). الموسوعة الاعلامية. القاهرة : دار الفجر للنشر والتوزيع / نسخة الكترونية موقع نيل

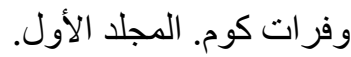

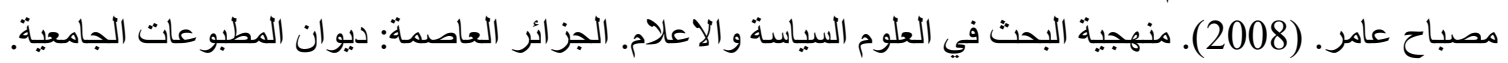

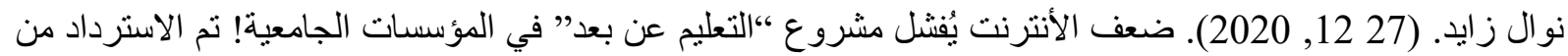
: https://cutt.us/d61OY النهار أون لاين 
و هيبة بوزيفي. (20 12, 2016). استخدام شبكات التواصل الاجتماعي في تعزيز العملية التعليمية. تم الاسترداد من مركز : https://cutt.us/2Hdwrist البحث العيل

Nassir Bouali, A. M. (2021). how to Read and Understand the Value Determinism Theory of the media? A semantic Structural Approach,. International Journal of English Literature and Social Sciences Vol6, Issue-2, 118-112. 